\title{
Photoelectrochemical Water Splitting: Thermal Annealing Challenges on Hematite Nanowires
}

\author{
Paula Quitério, Arlete Apolinário, David Navas, Sérgio Magalhães, Eduardo Alves, Adélio Mendes, \\ Célia Tavares Sousa, and João Pedro Araújo*
}

Cite This: J. Phys. Chem. C 2020, 124, 12897-12911

Read Online

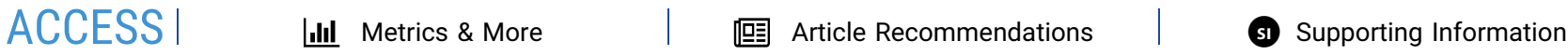

ABSTRACT: Hematite is getting great attention as an environmentally friendly material for photoelectrochemical water splitting, due to its narrow band gap $(1.9-2.2 \mathrm{eV})$, nontoxicity, low cost, high stability and wide availability. However, hematite shortcomings such as its low absorption coefficient, short hole diffusion length, or poor electrical conductivity lead to multiple electron-hole recombinations and efficiency losses. This work describes the preparation of nanostructured hematite photoelectrodes by a hydrothermal method followed by thermal annealing under different conditions. A large
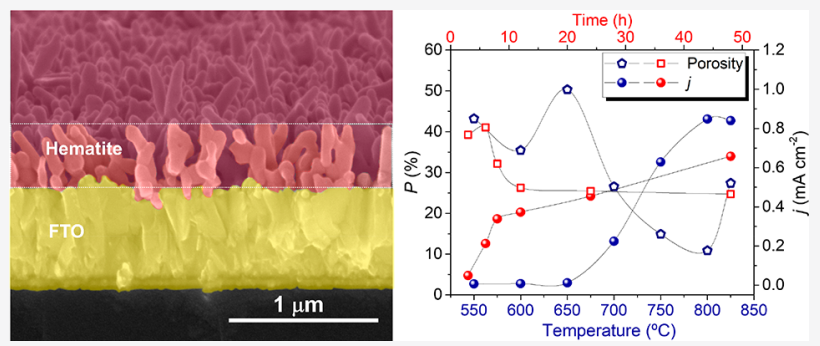
spectrum of materials science characterization techniques were used to unify the broad and underlying physical-chemical processes by which a material's structure and properties influence the performance of these photoelectrodes. In particular, Sn diffusion into hematite via a high-temperature annealing scheme is fairly analyzed by Rutherford backscattering spectrometry to assess the in-depth $\mathrm{Sn}$ distribution profiles and by extended X-ray absorption fine structure analysis for structural order analysis. The increase of photocurrent with annealing temperature and time, besides being related with percent $\mathrm{Sn}$ diffusion along the hematite photoelectrode, is also correlated with nanowires morphology, porosity features, and structural crystalline order enhancement. This study shows that an accurate combination of the semiconducting photoelectrode intrinsic properties, such as percent Sn profile content, one-dimensional nanowire diameter, porosity, and structural crystalline order, naturally leads to photoelectrodes with improved conductivity to photogenerated carriers and reduced band gap.

\section{INTRODUCTION}

Mankind is struggling to find effective approaches to climate changes that are reaching the brink of irreversibility. Hydrogen fuel, if produced from renewable resources such as water and sunlight, can be considered a sustainable and clean route for energy harvest and storage. ${ }^{1}$ Photoelectrochemical (PEC) cell devices for hydrogen production benefit from the possibility to use cost-effective materials and simple architectural designs compared with other technologies such as photovoltaic-driven electrolysis. ${ }^{2}$ The use of hematite $\left(\alpha-\mathrm{Fe}_{2} \mathrm{O}_{3}\right)$ photoanodes for PEC water splitting have been gathering considerable attention due to their abundance, low cost, nontoxicity, excellent longterm stability, and suitable band gap (1.9-2.2 eV), which could allow us to reach the theoretical solar-to-hydrogen conversion efficiency $(16.8 \%) .^{3-8}$ However, the performance of hematite is mainly limited by its poor conductivity $\left(\sim 10^{-14}\right.$ $\left.\Omega^{-1} \cdot \mathrm{cm}^{-1}\right)$, low carrier mobility $\left(\sim 10^{-2} \mathrm{~cm}^{2} \cdot \mathrm{V}^{-1} \cdot \mathrm{s}^{-1}\right)$, and short hole diffusion length $(2-4 \mathrm{~nm})^{9,10}$ that favor the high electron-hole recombination rates and significant efficiency losses. ${ }^{6,7,11}$ In order to overcome these limitations and enhance the PEC activity, nanostructured hematite photoanodes have been investigated as they have shown an increase in the electron transport, charge separation efficiency, and solar irradiation absorption. $^{6-8}$
One-dimensional (1D) nanostructures, such as nanowires (NWs) with high aspect ratios, have been suggested as potential candidates as they provide a more direct pathway for charge transportation up to the charge collector and reduce the recombination losses. ${ }^{6,7,12-15}$ Since 2001, when Vayssieres et al. ${ }^{16}$ demonstrated that hematite NWs can be easily prepared by hydrothermal method, several publications have shown that this methodology is the most effective one to increase the hematite photocurrent. ${ }^{6,7,12,13,15,17,18}$ In fact, a photocurrent of $\sim 6 \mathrm{~mA} \cdot \mathrm{cm}^{-2}$ was already achieved with NWs grown by a hydrothermal method, shortening the $12.9 \%$ photoconversion efficiency goal for hematite. ${ }^{3,18}$

Additionally, the use of dopants can highly increase the donor density improving the electrical conductivity of hematite. ${ }^{5,12,18-24}$ The doping of bare hematite can be performed by $\mathrm{Sn}$ diffusion from FTO (fluorine-doped tin oxide) substrate to the photoanode via a higher temperature

Received: February 13, 2020

Revised: $\quad$ May 19, 2020

Published: May 19, 2020 
Table 1. Sets of Samples Prepared with Different Annealing Conditions

\begin{tabular}{|c|c|c|c|c|c|c|c|}
\hline \multirow{3}{*}{$\begin{array}{c}\text { set } \\
\text { temperature }\left({ }^{\circ} \mathrm{C}\right)\end{array}$} & \multicolumn{3}{|c|}{ one-step annealing } & \multicolumn{4}{|c|}{ two-step annealing } \\
\hline & \multirow{2}{*}{$\begin{array}{c}1 \\
600-850\end{array}$} & \multirow[b]{2}{*}{800} & \multirow{2}{*}{$\begin{array}{l}3 \\
600\end{array}$} & \multicolumn{2}{|c|}{4} & \multicolumn{2}{|c|}{5} \\
\hline & & & & 550 & 800 & 550 & $600-825$ \\
\hline time (units) & $20(\min )$ & $5-25(\mathrm{~min})$ & $3-72(\mathrm{~h})$ & $2(\mathrm{~h})$ & $20(\min )$ & $2(\mathrm{~h})$ & $20(\mathrm{~min})$ \\
\hline $\operatorname{ramp}\left({ }^{\circ} \mathrm{C} \cdot \min ^{-1}\right)$ & $\mathrm{WR}^{a}$ & $\mathrm{WR}^{a}$ & 10 & $1-10 ; \mathrm{WR}^{a}$ & 8 & 10 & 8 \\
\hline
\end{tabular}

${ }^{a} \mathrm{WR}$ : without ramp (i.e., sample placed directly in the furnace at the established temperature).

annealing process (generally $\left.750-800{ }^{\circ} \mathrm{C}\right) . .^{12,13,17,19,21,25} \mathrm{Sn}$ diffusion in the order of $0.9-9.9 \%$ (atomic \%) was observed. This led to a conductivity improvement and to a photocurrent increase from 0.035 up to $1.24 \mathrm{~mA} \cdot \mathrm{cm}^{-2}$ [at $1.23 \mathrm{~V}$ vs reversible hydrogen electrode $\left.\left(\mathrm{V}_{\mathrm{RHE}}\right)\right]$ when the annealing temperature varied from 550 to $800{ }^{\circ} \mathrm{C} .{ }^{12}$ Although a higher annealing temperature $\left(\sim 1000{ }^{\circ} \mathrm{C}\right)$ is required for the complete conversion of hematite, ${ }^{25,26}$ the use of activation temperatures higher than $800{ }^{\circ} \mathrm{C}$ is limited by FTO deformation. ${ }^{12,13,17,19}$

Thermal annealing promotes Sn diffusion which increases the electron donor density but also eliminates internal and superficial defects improving the hematite crystalline structure and reducing the surface recombination. ${ }^{17,25,27,28}$ The improved photoconversion performance results from both the morphological anisotropy of the precursor $\beta$-FeOOH NWs and the annealing temperature. ${ }^{17,25,27}$ However, it should be noted that the larger particle size usually obtained with higher annealing temperatures, along with the short hole diffusion length $(2-4 \mathrm{~nm})$, strongly limits the photoconversion efficiencies. $^{12,13,25,29}$

Moreover, other factors like the annealing atmosphere ${ }^{18,30,31}$ or concentration of oxygen vacancies ${ }^{31-33}$ have also been studied. Some discrepancies were observed in terms of annealing steps: While some authors reported the use of one-step annealing, ${ }^{13,19,34,35}$ others used a first step at 500$550{ }^{\circ} \mathrm{C}$ to convert the $\beta$-FeOOH (iron oxyhydroxide) phase into hematite followed by a second shorter step at higher temperatures (between 750 and $800{ }^{\circ} \mathrm{C}$ ) for the hematite activation. $^{12,19,22,31,36,37}$ The effect of performing a rapid cooling process should be also mentioned as beneficial for the charge separation efficiency, improving the photocurrent values. ${ }^{38}$

Likewise, annealing time is an underestimated parameter, rarely reported and generally limited by substrate deformation. ${ }^{13}$ However, the use of low-cost substrates with extended annealing time should be relevant for industrial applications. The influence of prolonged annealing time in morphology, crystallinity, electronic structure, and photoactivity of NWs was not systematically studied so far.

In the present work, hematite NWs were prepared by a hydrothermal method, varying the annealing conditions for the formation of the $\alpha-\mathrm{Fe}_{2} \mathrm{O}_{3}$ crystalline phase. The influences of the annealing steps, heating ramp, temperature, and time on the performance of the hematite nanostructured photoelectrodes were intensively studied and related with the morphology, crystalline structure, and optical properties. Here, the use of $600{ }^{\circ} \mathrm{C}$ for prolonged annealing time (without the FTO deformation) allows the use of low-cost substrates, without a decrease in the photocurrent values. This study determined that the annealing conditions do influence and cause different impacts on the photoelectrodes performance.

\section{EXPERIMENTAL SECTION}

2.1. Hematite Photoanodes Preparation. FTO glass substrates (Solaronix, 7 and $10 \Omega$ square $^{-1}$ ) were cleaned as described elsewhere ${ }^{39}$ and then placed in a $40 \mathrm{~mL}$ capacity Teflon stainless-steel autoclave with $20 \mathrm{~mL}$ of a solution comprising $0.15 \mathrm{M} \mathrm{FeCl} \cdot 6 \mathrm{H}_{2} \mathrm{O}(99+\%)$ and $1 \mathrm{M}$ $\mathrm{NaNO}_{3}(\geq 99.0 \%)$. The solution was adjusted to $\mathrm{pH} 1.5$ using $\mathrm{HCl} 37 \%$. The autoclave was heated at $95{ }^{\circ} \mathrm{C}$ for $4 \mathrm{~h}$ in order to obtain iron oxide NWs. ${ }^{12}$ After hydrothermal growth, a yellow film layer of iron oxyhydroxide NWs was formed on the FTO substrates. Then, a thermal annealing was necessary to obtain the $\alpha-\mathrm{Fe}_{2} \mathrm{O}_{3}$ phase. Although hematite crystallization starts above $390{ }^{\circ} \mathrm{C}$, the ideal annealing temperature for complete conversion into hematite was reported to occur at $\sim 1000{ }^{\circ} \mathrm{C}$. ${ }^{16,26}$ Unfortunately, the destruction of the FTO substrates occurs at temperatures above $825{ }^{\circ} \mathrm{C}$. Therefore, we used 550 and $825{ }^{\circ} \mathrm{C}$ as the starting and maximum annealing temperatures, respectively.

To investigate the effect of the annealing conditions on the photoelectrodes photoperformance, several annealing parameters were studied: heating ramp, one-step versus two-step annealing approach, temperature, and time. ${ }^{12,13,22,27,34}$ The preparation conditions are summarized in Table 1. For the two-step annealing approach, we performed a first annealing at $550{ }^{\circ} \mathrm{C}$ during $2 \mathrm{~h}$, followed by a short annealing step $(20 \mathrm{~min})$ at higher temperatures $\left(600-825^{\circ} \mathrm{C}\right) \cdot{ }^{12,19,22,31,36,37}$

2.2. Photoelectrochemical Characterization. 2.2.1. Photocurrent Density-Voltage Curves. The photocurrent-voltage $(j-V)$ curves under dark and 1 sun simulated sunlight $\left(100 \mathrm{~mW} \cdot \mathrm{cm}^{-2}\right.$, AM $\left.1.5 \mathrm{G}\right)$ were performed using a class B solar simulator with a $150 \mathrm{~W}$ Xe lamp (Oriel, Newport). Measurements were performed using a "cappuccino" PEC cell, ${ }^{4,40}$ filled with a $1.0 \mathrm{M} \mathrm{NaOH}$ electrolyte solution. The illuminated surface area was $0.528 \mathrm{~cm}^{2}$, and a threeelectrode configuration was used: $\mathrm{Ag} / \mathrm{AgCl} /$ saturated $\mathrm{KCl}$ electrode as the reference electrode, a platinum wire as the counter-electrode, and the hematite NWs photoelectrodes as the working electrode.

2.2.2. Determination of Intrinsic Solar to Chemical Conversion Efficiency. The intrinsic solar to chemical (ISTC) conversion efficiency was determined based on the model proposed by Rothschild et al., from the photocurrent density versus potential curves measured under dark and illumination, in a three-electrode configuration. ${ }^{4,41}$ The ISTC can be defined as

$$
\begin{aligned}
\text { ISTC } & =\left[\eta_{\mathrm{el}} \frac{J_{\text {photo }}\left(\mathrm{mA} \cdot \mathrm{cm}^{-2}\right) \times V_{\text {photo }}(\mathrm{V})}{P_{\text {light }}\left(\mathrm{mW} \cdot \mathrm{cm}^{-2}\right)}\right]_{\mathrm{AM} 1.5 \mathrm{G}} \\
& \cong \frac{1.23\left(\mathrm{~V}_{\mathrm{RHE}}\right)}{U_{\text {dark }}\left(\mathrm{V}_{\mathrm{RHE}}\right)}\left[\frac{J_{\text {photo }}\left(\mathrm{mA} \cdot \mathrm{cm}^{-2}\right) \times V_{\text {photo }}(\mathrm{V})}{100 \mathrm{~mW} \cdot \mathrm{cm}^{-2}}\right]_{\mathrm{AM} 1.5 \mathrm{G}}
\end{aligned}
$$


a)

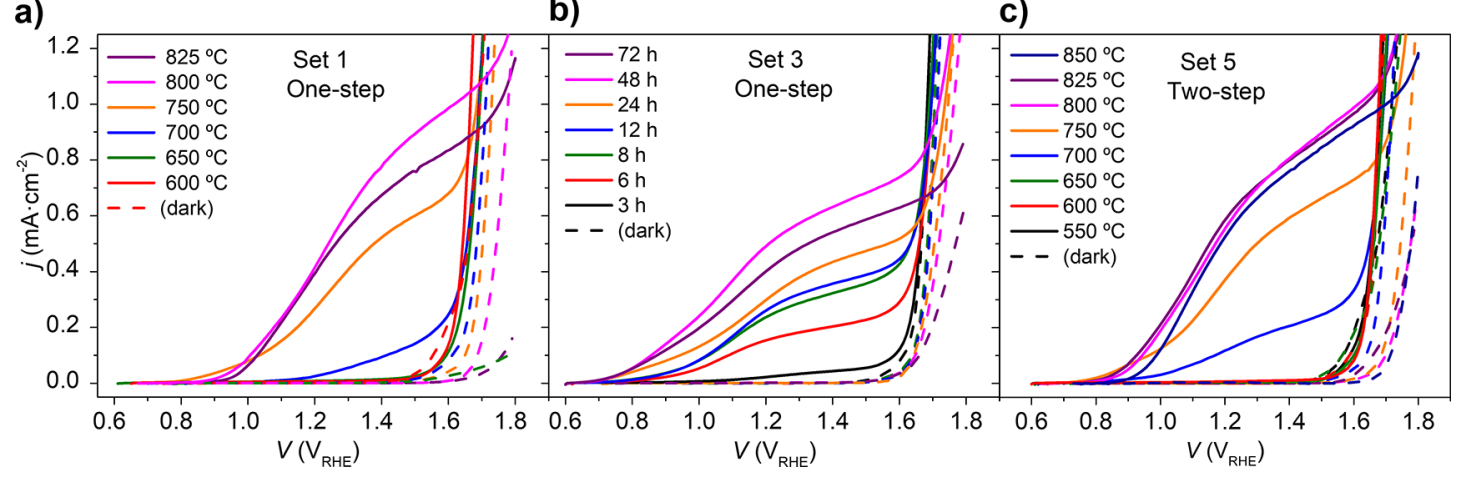

Figure 1. $j-V$ characteristic curves for $\alpha$ - $\mathrm{Fe}_{2} \mathrm{O}_{3}$ samples with different annealing steps (a) set 1: samples prepared with different temperatures $\left(600-825^{\circ} \mathrm{C}\right)$ for $20 \mathrm{~min},(\mathrm{~b})$ set 3: samples prepared with different time $(3-72 \mathrm{~h})$ at $600{ }^{\circ} \mathrm{C}$, (c) set 5: samples prepared with two-step annealing, $550{ }^{\circ} \mathrm{C}$ for $2 \mathrm{~h}$ followed by $20 \mathrm{~min}$ at $600-825^{\circ} \mathrm{C}$.

where $\eta_{\mathrm{el}}$ is the electrolysis efficiency, $J_{\text {photo }}$ is the generated photocurrent, $V_{\text {photo }}$ is the correspondent photopotential, and $U_{\text {dark }}$ is the potential necessary to be applied to the photoanode to reach the respective current in the dark. ${ }^{4,41}$

In addition, the intrinsic photovoltaic power $P_{\text {light }}$ for the photoanodes was determined by the relation:

$$
P_{\text {light }}\left(\mathrm{mW} \cdot \mathrm{cm}^{-2}\right)=J_{\text {photo }}\left(\mathrm{mA} \cdot \mathrm{cm}^{-2}\right) \times V_{\text {photo }}(\mathrm{V})
$$

The fill factor (FF) at the maximum power point was determined by the equation:

$$
\mathrm{FF}=\frac{V_{\mathrm{PP}} \times J_{\mathrm{PP}}}{V_{\mathrm{OC}} \times J_{\mathrm{SC}}}
$$

where $V_{\mathrm{PP}}$ and $J_{\mathrm{PP}}$ are the values of photopotential and photocurrent at the maximum power point, respectively; $V_{\mathrm{OC}}$ and $J_{S C}$ represent the open-circuit voltage and short-circuit current, respectively.

2.3. Morphological Characterization. The morphological characterization was performed using scanning electron microscopy (SEM, FEI Quanta 400FEG Field Emission; at CEMUP, University of Porto). Using ImageJ, ${ }^{42}$ we measured the NWs diameter, $D$, and thickness, $L$, taken respectively from SEM top-view and cross-sectional images.

2.4. Structural Characterization. To further explore the relation between the photocurrent density $j$ and the morphology of the samples with different annealing conditions, $\mathrm{X}$-ray crystallographic analysis was carried out. The structural analysis was performed using an X-ray diffractometry (XRD, Rigaku SmartLab) with $\mathrm{Cu} \mathrm{K} \alpha$ radiation (1.540593 $\AA$ ) in parallel-beam (PB) mode with grazing incidence (PBGI) angles.

The information about the local structure and the oxidation state of the samples was obtained by X-ray absorption nearedge structure (XANES) and extended X-ray absorption finestructure (EXAFS) analyses. These experiments were performed at the XAFS2 beamline of Brazilian Synchrotron Light Laboratory (LNLS); this beamline operates with a 1.37 $\mathrm{GeV}$ source, a maximum current of $250 \mathrm{~mA}$, and a critical energy of $2.08 \mathrm{keV}$ and delivers photons in the range of 3.5-17 $\mathrm{keV}^{43}$ Samples were measured on the $\mathrm{Fe} k$-edge, in fluorescence mode, and compared with several iron oxide powder references measured in transmission mode. XANES and EXAFS data were analyzed using ATHENA and ARTEMIS software. ${ }^{44}$
Rutherford backscattering spectrometry (RBS) analysis was performed to determine the in-depth profile distribution of the atomic elements, using a Van de Graaff accelerator with 2.0 $\mathrm{MeV} 4 \mathrm{He}^{+}(\alpha)$ particles. The backscattered particles were collected at $+165,-140$, and $-165^{\circ}$ using silicon $\mathrm{p}$-i-n diode detectors, and random spectra were taken by tilting samples at three different angles $\left(\theta=5,20,30^{\circ}\right)$ for more accurate data analysis. Simulations and fitting were performed using the NDF code; ${ }^{45,46}$ parameters such as roughness and volume fraction (voids) were considered.

2.5. Optical Characterization. UV-visible absorption data were collected using an UV-vis-near-infrared (NIR) spectrophotometer (Shimadzu Scientific Instruments Inc., model UV-3600, Kyoto). The absorbance spectra were calculated subtracting the reflectance and transmittance spectra to the incident radiation and corrected by subtracting the FTO absorbance. ${ }^{4,40}$

\section{RESULTS AND DISCUSSION}

3.1. Photoelectrochemical Performance. The photoelectrochemical performance of the hematite photoanodes was assessed based on the photocurrent density-voltage $(j-V)$ curves. Figure $1 \mathrm{a}-\mathrm{c}$ shows the $j-V$ characteristic curves under dark and simulated sunlight for sets 1,3 , and 5 of $\alpha-\mathrm{Fe}_{2} \mathrm{O}_{3}$ photoanodes described in the previous section (see Table 1 ). The $j-V$ curves for the remaining sets 2 and 4 are displayed in Figure S1a,b. The photocurrent was assessed under front-side illumination, which resulted in higher photocurrent than backside illumination, as the majority carriers (electrons) have less transport limitations within hematite photoelectrodes than minority carriers (holes). The transport of generated electrons from the illuminated hematite side through the FTO direction is easier than the contrary trajectory that holes (with a short diffusion length of $2-4 \mathrm{~nm}$ ) would have to travel if photoelectrodes were back-illuminated. ${ }^{8}$ For the one-step annealing photoelectrodes (set 1), the photocurrent density (j) increases with temperature until it reaches $800{ }^{\circ} \mathrm{C}$ (Figure 1a). Above this temperature, the $j$ decrease can be attributed to the FTO substrate deformation, since glass bending was visually observed. These results confirm that $800{ }^{\circ} \mathrm{C}$ is the best annealing temperature. ${ }^{12}$ Fixing the annealing temperature at $800{ }^{\circ} \mathrm{C}$ and varying the time between 5 and $25 \mathrm{~min}$ (set 2 ), the $j-V$ curves show that $20 \mathrm{~min}$ seems to be the ideal annealing time before causing FTO substrate deformation and consequently the decrease of $j$ (see Figure S1a). In the same way, when the annealing temperature is set at $600{ }^{\circ} \mathrm{C}$ and the 
annealing time is varied between 3 and $72 \mathrm{~h}$ (set 3 ), $j$ increases with time up to $48 \mathrm{~h}$ (Figure $1 \mathrm{~b}$ ). Afterward, a decrease of $j$ is observed $(t=72 \mathrm{~h}$ ), and some FTO bending was observed.

Regarding the two-step annealing photoelectrodes prepared with different annealing ramps (set 4 ), although no significant differences are observed, the $10^{\circ} \mathrm{C} \cdot \mathrm{min}^{-1}$ ramp shows a slight better $j$ performance (Figure S1b). According to these results, we carried out a first annealing step at $550{ }^{\circ} \mathrm{C}$, followed by a second annealing step ranging the applied temperatures between 600 and $850{ }^{\circ} \mathrm{C}$ (set 5). In this set, $j$ increases with temperature up to $800{ }^{\circ} \mathrm{C}$ (Figure 1c), as already observed for set 1 (in Figure 1a). The $825^{\circ} \mathrm{C}$ sample resulted in similar $j$ values and was considered for characterization. Above this temperature, a decrease in $j$ is also observed due to the same reason of FTO deformation mentioned above. The samples with annealing at $850{ }^{\circ} \mathrm{C}$ and $72 \mathrm{~h}$ were not considered for further characterization in this work.

Figure 2a shows the evolution of $j$ (at $1.45 \mathrm{~V}_{\mathrm{RHE}}$ ) as a function of temperature for both one- and two-step annealing
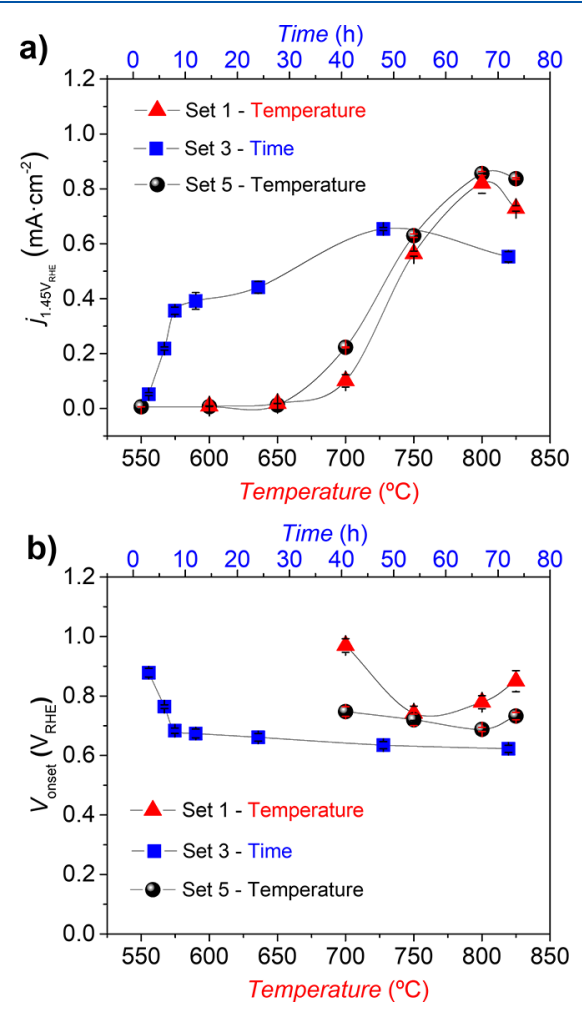

Figure 2. (a) $j$ at $1.45 \mathrm{~V}_{\mathrm{RHE}}$ and (b) $V_{\text {onset }}$ for hematite photoanodes from sets 1,3 , and 5 .

processes (sets 1 and 5, respectively). Although they exhibit similar behaviors, slight higher $j$ performance values are obtained for $>650{ }^{\circ} \mathrm{C}$ when the two-step annealing process was used. Regarding the onset potential $V_{\text {onset }}$ (Figure $2 \mathrm{~b}$ ), we observe a decrease by increasing the annealing temperature. It was suggested that lower $V_{\text {onset }}$ corresponds to the reduction of the surface trap states by annealing temperature (attributed to the passivation of surface states just beneath the conduction band) and, consequently, recombination processes. It also has been attributed to the use of dopants/catalysts surface modification. ${ }^{12,13,27,47}$ According to this idea, a favorable cathodic shift to lower potentials is observed for photoelectrodes with two-step annealing (set 5). Likewise, $V_{\text {onset }}$ also decreases as the temperature increases (Figure 2b). In particular, it should be noticed that $j$ is significantly low, $\sim 0.01 \mathrm{~mA} \cdot \mathrm{cm}^{-2}$, when the sample was annealed at $550{ }^{\circ} \mathrm{C}$ for $2 \mathrm{~h}$ and improves to $0.85 \mathrm{~mA} \cdot \mathrm{cm}^{-2}$ with the second annealing step at $800{ }^{\circ} \mathrm{C}$, in accordance with the typical $j$ values of bare hematite. ${ }^{13,21,22,24,36}$ Such behavior goes with a minimum value of $V_{\text {onset }}=0.68 \mathrm{~V}_{\mathrm{RHE}}$.

By increasing the annealing time at $600{ }^{\circ} \mathrm{C}$ (set 3 ), Figure 2a shows that $j$ gradually increases up to $48 \mathrm{~h}$ and reaches a maximum value of $0.66 \mathrm{~mA} \cdot \mathrm{cm}^{-2}$. This value is 66 times higher than the one measured for the sample with two-step annealing (set 5) using the same temperature $\left(550{ }^{\circ} \mathrm{C}\right.$ for $2 \mathrm{~h}+600{ }^{\circ} \mathrm{C}$ for $20 \mathrm{~min}$ ). Moreover, this $j$ is similar to the values achieved by the samples treated at $750{ }^{\circ} \mathrm{C}$ (see Figure 2a) and with a lower onset potential: $V_{\text {onset } 48 \mathrm{~h}}=0.62 \mathrm{~V}_{\mathrm{RHE}}$ versus $V_{\text {onset }} 750^{\circ} \mathrm{C}$ $=0.70 \mathrm{~V}_{\mathrm{RHE}}$ (Figure $2 \mathrm{~b}$ ). Therefore, the application of $600^{\circ} \mathrm{C}$ for $48 \mathrm{~h}$ may allow use of substantially cheaper FTO substrates, important to the scale-up of hematite photoanodes. Further annealing time revealed a $j$ decrease, $0.57 \mathrm{~mA} \cdot \mathrm{cm}^{-2}$ at $72 \mathrm{~h}$ (Figure 2a). Furthermore, the onset potential decreases with annealing time from 0.89 to $0.62 \mathrm{~V}_{\mathrm{RHE}}$ for $3-48 \mathrm{~h}$, respectively (Figure 2b).

In summary, sets 3 (time dependence) and 5 (temperature dependence) showed the most relevant results confirming that $j$ depends mainly on both the annealing temperature and time. Thus, we will focus our attention on these two sets of samples (sets 3 and 5) in order to try to unveil the role of annealing temperature and time in the hematite photoanodes performance.

3.1.1. Intrinsic Solar to Chemical Conversion Efficiency. The intrinsic solar to chemical (ISTC) conversion efficiency was determined for the photoelectrodes with the best $j-V$ performance in each annealing scheme, temperature, and time $\left(800{ }^{\circ} \mathrm{C}\right.$ and $\left.48 \mathrm{~h}\right)$, in order to evaluate the efficiency of these photoelectrodes in the conversion of photonic into chemical energy required for water oxidation. ${ }^{4}$ First, the photocurrent $\left(J_{\text {photo }}\right)$ and photopotential $\left(V_{\text {photo }}\right)$ were extracted from the $j-$ $V$ curves, determined by the difference between the light and dark currents and potentials, respectively (as illustrated by the black arrows in Figure 3a). After calculating $J_{\text {photo }}$ and $V_{\text {photo }}$ from the $j-V$ curves, $J_{\text {photo }}$ was plotted as a function of the $V_{\text {photo }}$. This yields the photocurrent density measured under short-circuit conditions $\left(J_{\mathrm{sc}}\right)$ and the open-circuit photopotential $\left(V_{\text {oc }}\right)$, Figure $3 \mathrm{~b}$. The intrinsic photovoltaic power of the photoelectrodes (represented in Figure $3 \mathrm{c}$ as $P_{\text {light }}$ ) is given by the product of $J_{\text {photo }}$ by $V_{\text {photo }}$ (eq 2). By plotting this versus $V_{\text {photo }}$ the maximum power point (MPP) can be obtained as well as the respective voltage $\left(V_{\mathrm{PP}}\right)$ and current $\left(J_{\mathrm{PP}}\right)$.

For the $800{ }^{\circ} \mathrm{C}$ photoelectrode, it was obtained a maximum power of $0.35 \mathrm{~mW} \cdot \mathrm{cm}^{-2}$ at a potential $U_{\text {light }}$ of $1.3 \mathrm{~V}_{\mathrm{RHE}}$, i.e., the potential applied to the photoelectrode under light (represented in the secondary $y$-axis, Figure 3c). This corresponds to a maximum power conversion efficiency of $0.35 \%$ for $800{ }^{\circ} \mathrm{C}$, which means that this sample generated an electric power of $0.35 \mathrm{~mW} \cdot \mathrm{cm}^{-2}$ from the solar-simulated light power of $100 \mathrm{~mW} \cdot \mathrm{cm}^{-2}$. A maximum power of $0.25 \%$ (at $U_{\text {light }}$ $=1.2 \mathrm{~V}_{\mathrm{RHE}}$ ) was obtained for the $48 \mathrm{~h}$ photoanode. From eq 3 , the fill factor (FF) was determined. FFs of 46.6 and $45 \%$ at the maximum power point were obtained for the $800{ }^{\circ} \mathrm{C}$ and $48 \mathrm{~h}$ photoelectrodes, respectively, in accordance with the values usually reported for hematite. ${ }^{4,41}$ The FF for both samples is quite similar which may indicate that the $48 \mathrm{~h}$ photoelectrode 

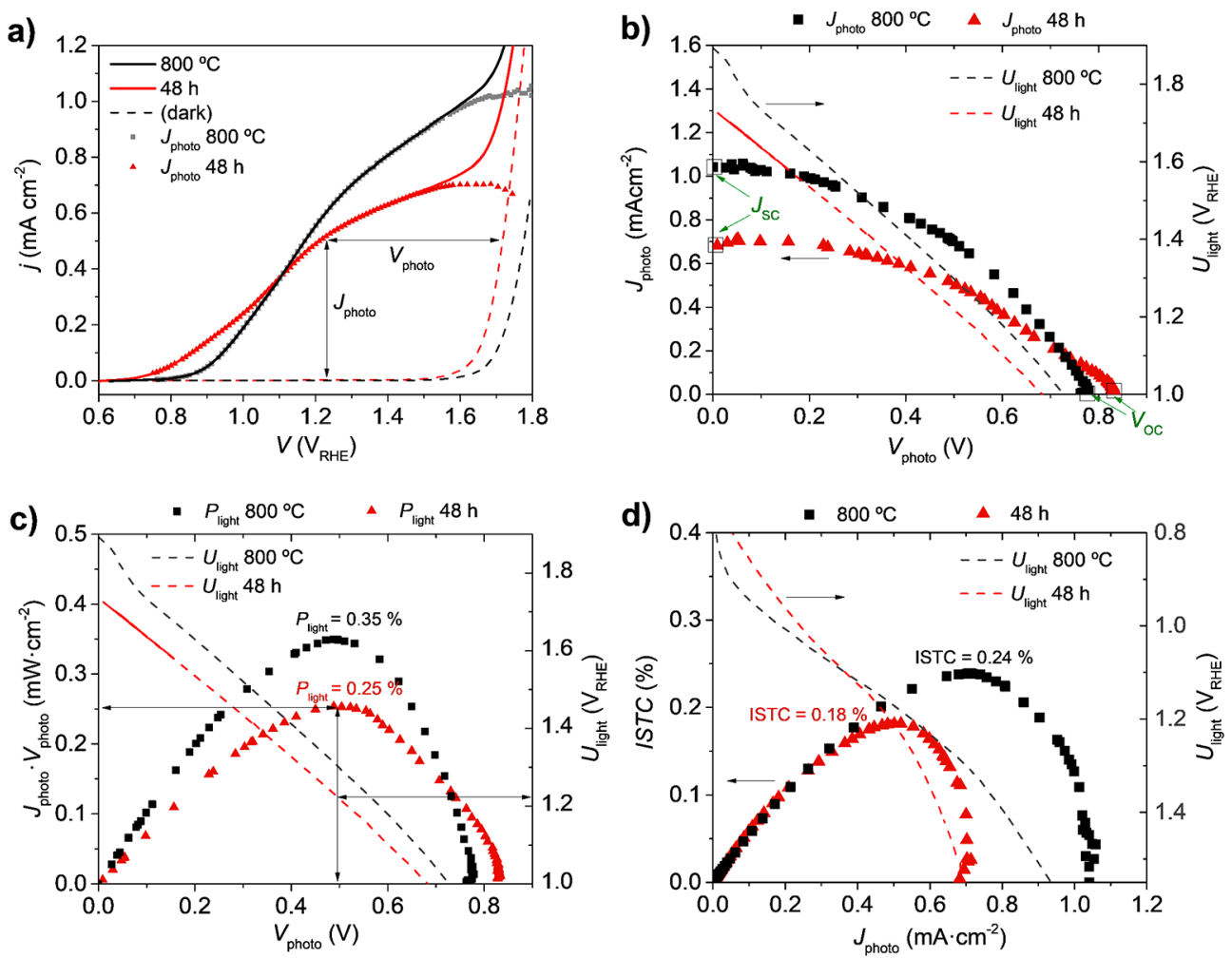

Figure 3. (a) $j-V$ curves for the $800{ }^{\circ} \mathrm{C}$ and $48 \mathrm{~h}$ photoelectrodes, obtained in the dark (dashed lines) and simulated solar illumination (solid lines) and the respective photocurrent, $J_{\text {photo }}$. (b) Photocurrent $\left(J_{\text {photo }}\right)$ as a function of the photopotential $\left(V_{\text {photo }}\right)$. (c) Intrinsic photovoltaic power $\left(P_{\text {light }}\right)$ as a function of $V_{\text {photo }}$ (d) ISTC efficiencies as a function of $J_{\text {photo }}$. The secondary $y$-axes on the right sides of panels b-c are used to plot the potential $\left(U_{\text {light }}\right)$ applied to the photoanode under light.

is not particularly more affected by factors such as charge recombination or low charge extraction. ${ }^{48,49}$

Figure $3 \mathrm{~d}$ shows the plot of ISTC conversion efficiency for both photoelectrodes as a function of $J_{\text {photo }}$. For the $800{ }^{\circ} \mathrm{C}$ and $48 \mathrm{~h}$, ISTC maximum efficiencies of $0.25 \%$ (at $J_{\text {photo }}$ of $0.71 \mathrm{~mA} \cdot \mathrm{cm}^{-2}$ and $U_{\text {light }}$ of $1.3 \mathrm{~V}_{\mathrm{RHE}}$ ) and $0.18 \%$ (at $J_{\text {photo }}$ of $0.52 \mathrm{~mA} \cdot \mathrm{cm}^{-2}$ and $U_{\text {light }}$ of $1.2 \mathrm{~V}_{\mathrm{RHE}}$ ) were obtained, respectively. In order to obtain the same photocurrent values in the dark, it would require potentials of 1.8 and $1.72 \mathrm{~V}_{\mathrm{RHE}}$, respectively, for the $800{ }^{\circ} \mathrm{C}$ and $48 \mathrm{~h}$ photoelectrodes (taken from the $j-V$ dark curves in Figure $3 \mathrm{a}$ ). This indicates that the simulated solar light power $\left(100 \mathrm{~mW} \cdot \mathrm{cm}^{-2}\right)$ saves $0.49 \mathrm{~V}$ from the external power source, i.e., a power of $0.49 \mathrm{~V} \times 0.71 \mathrm{~mA}$. $\mathrm{cm}^{-2}=0.35 \mathrm{~mW} \cdot \mathrm{cm}^{-2}$ in the case of the $800{ }^{\circ} \mathrm{C}$ photoelectrode and $0.48 \mathrm{~V}$ in the case of the $48 \mathrm{~h}$ sample. However, a reduction of the electric power saved is caused by the conversion efficiency of the electrolysis reaction, $\eta_{\mathrm{el}}$. From eq $1, \eta_{\mathrm{el}} \cong 1.23\left(\mathrm{~V}_{\mathrm{RHE}}\right) / U_{\mathrm{dark}}\left(\mathrm{V}_{\mathrm{RHE}}\right)$, which gives $\eta_{\mathrm{el}}\left(800^{\circ} \mathrm{C}\right)=$ $68.33 \%$ and $\eta_{\mathrm{el}}(48 \mathrm{~h})=71.51 \%$. Therefore, the light-induced contribution to the chemical power produced by the $800{ }^{\circ} \mathrm{C}$ photoanode is $0.24 \mathrm{~mW} \cdot \mathrm{cm}^{-2}\left(68.33 \% \times 0.35 \mathrm{~mW} \cdot \mathrm{cm}^{-2}\right)$, while for $48 \mathrm{~h}$ it gives a value of $0.18 \mathrm{~mW} \cdot \mathrm{cm}^{-2}(71.51 \% \times$ $\left.0.25 \mathrm{~mW} \cdot \mathrm{cm}^{-2}\right)$, corresponding to ISTC efficiencies of 0.24 and $0.18 \%$ respectively. Thus, the ISTC of the photoelectrodes is given by the product of the electrolysis efficiency with the internal power, of which the maximum point determines the optimum operating conditions for the PEC cell. ${ }^{4,41}$ These calculations yield the potential that should be applied to the photoanode in order to ensure the intrinsic conversion of solar to chemical power at its maximum conversion efficiency. The obtained values are in deep accordance with the literature for hematite photoelectrodes. ${ }^{4,41}$

3.2. Morphological Performance. From the SEM images (Figure $4 a-i)$, morphological changes were observed with annealing temperature and time. The measured diameter $(D)$ and thickness $(L)$ are illustrated in Figure $4 a, b$, respectively. The iron oxide NWs are entirely formed at the first stage of hydrothermal growth process (shown in Figure 4c). At this stage, the NWs show a needle form, with square-shaped tips.

However, after the annealing treatment at $550{ }^{\circ} \mathrm{C}$, the nanostructures became slightly porous, where the NWs show a shape that is more rounded, smoother, and without any clear changes in $D$ (Figure $4 \mathrm{~d}$ ). After the application of the second annealing step (from 600 up to $825^{\circ} \mathrm{C}$ ), the $\mathrm{NWs}$ shape becomes rounder and $D$ increases (Figure $4 \mathrm{e}, \mathrm{f}$ for 700 and 800 ${ }^{\circ} \mathrm{C}$ samples, respectively). As the annealing temperature was increased, the fusion between neighboring NWs ${ }^{12,13}$ seems to take place, increasing $D$ almost linearly from 42 to $97 \mathrm{~nm}$ for $550-800{ }^{\circ} \mathrm{C}$ (Figure 5a).

Regarding the annealing time, a similar behavior was observed: $D$ increases with time, and the shape becomes rounder, especially above $8 \mathrm{~h}$. Again, the fusion between NWs, induced by the timely continuous annealing at fixed temperature (Figure $4 \mathrm{~g}-\mathrm{i}$ for 6,24 , and $48 \mathrm{~h}$, respectively) can be suggested. A small $D$ increase with annealing time is observed up to $12 \mathrm{~h}$ (from 61 to $82 \mathrm{~nm}$ ); afterward, $D$ tends to keep a constant value for longer annealing time (Figure $5 b$ ).

Likewise, with the increase of annealing temperature and time, it was noticed a euhedral shape, where the crystal contours and faces became more defined (suggesting more crystalline structures; Figure $4 \mathrm{e}, \mathrm{f}, \mathrm{h}, \mathrm{i}) .{ }^{12,13}$ The transformation 

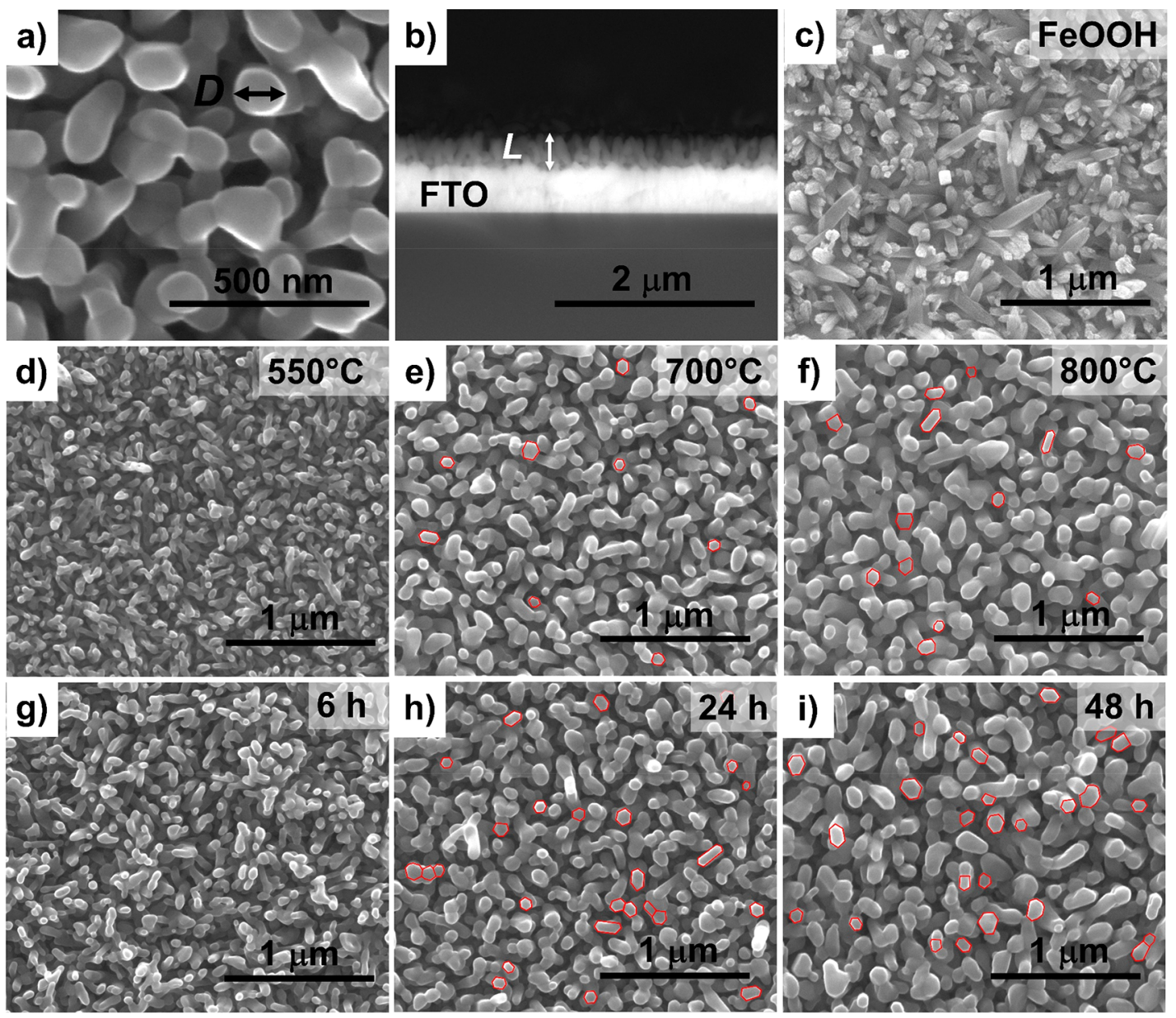

Figure 4. SEM images of (a) illustrative measurement of $\alpha-\mathrm{Fe}_{2} \mathrm{O}_{3} \mathrm{NWs}$ diameter (D) and (b) illustrative cross-section measurement of NWs thickness $(L)$. (c) FeOOH NWs after the hydrothermal synthesis. $\alpha$ - $\mathrm{Fe}_{2} \mathrm{O}_{3} \mathrm{NWs}$ with different annealing temperatures of $(\mathrm{d}) 550{ }^{\circ} \mathrm{C},(\mathrm{e}) 700{ }^{\circ} \mathrm{C}$, and (f) $800{ }^{\circ} \mathrm{C}$, and different annealing times of (g) $6 \mathrm{~h}$, (h) $24 \mathrm{~h}$, and (i) $48 \mathrm{~h}$. Panels e, f, h, and i show the demarked contours (in red) of euhedral structures.

became more evident with the $800{ }^{\circ} \mathrm{C}$ and $48 \mathrm{~h}$ annealing conditions.

The NWs thickness $(L)$ was determined from the SEM cross-sectional images (Figure S2). According to the literature, ${ }^{1,50}$ it is expected that a reduced thickness makes the electrons' pathway to reach the charge collector easier (due to the shorter distance), with less probability of electron-hole recombination. In this work, it was observed that $L$ slightly decreases with the annealing temperature (from $330 \pm 50 \mathrm{~nm}$ to $285 \pm 37 \mathrm{~nm}$ for 550 and $800{ }^{\circ} \mathrm{C}$, respectively). However, $L$ did not vary significantly with annealing time (from $262 \pm 52$ $\mathrm{nm}$ to $281 \pm 38 \mathrm{~nm}$, for 3 and $48 \mathrm{~h}$, respectively). Although more details can be seen in Figure S2, this aspect will be further discussed in section 3.4.

3.3. Structural Characterization. 3.3.1. X-ray Diffraction Analysis. From the XRD spectra (Figure 6a,b), the crystalline phase of the iron oxide NWs was determined. The use of a parallel beam $(\mathrm{PB})$ with grazing incident omega $(\omega)$ angles allows almost total removal of the FTO signal, usually the more intense one in the literature. ${ }^{12,13,18,20-22}$ After hydrothermal growth, the NWs present a peak with (211) orientation (Figure 6a) corresponding to the $\beta$-FeOOH phase (Joint Committee on Powder Diffraction Standards, Diffraction Data File No. 34-1266, JCPDS International Center for Diffraction Data, Pennsylvania, 1984). ${ }^{20}$ For both sets of samples and after the annealing treatment, the thermodynamically stable hematite phase (Joint Committee on Powder Diffraction Standards, Diffraction Data File No. 33664, JCPDS International Center for Diffraction Data, Pennsylvania, 1983), described as corundum crystalline structure with a hexagonal closed-packed unit cell, was obtained (Figure 6a,b), with the preferential orientation at diffraction peak (110). ${ }^{12,25,51,52}$ Also, other peaks indexed to $\alpha$ $\mathrm{Fe}_{2} \mathrm{O}_{3}$ structure, such as (012), (104), (024), (214), or (300) were identified. For temperatures above $800{ }^{\circ} \mathrm{C}\left(825{ }^{\circ} \mathrm{C}\right)$, a peak (200) of $\mathrm{SnO}_{2}$ from the FTO substrate increases (marked as $*$ in Figure $6 \mathrm{a})$. This can be attributed to two main reasons: (i) FTO at this range of temperature presents more signs of deformation and higher roughness, and it is technically more difficult to isolate the peak. (ii) We are using grazing angle diffraction (superficial incidence in sample) and are probably detecting more the FTO substrate or the interface FTO substrate/hematite (with higher $\mathrm{Sn}$ concentration diffused from FTO).

XRD spectra were fitted using pseudo-Voigt peak functions. The peak (104) has been usually related with the existence of oxygen vacancies acting as electron trapping sites and recombination centers. Moreover, the low mobility of electrons and holes within the (104) plane explains its low conductivity. ${ }^{11}$ The intensity of this peak decreases with the 

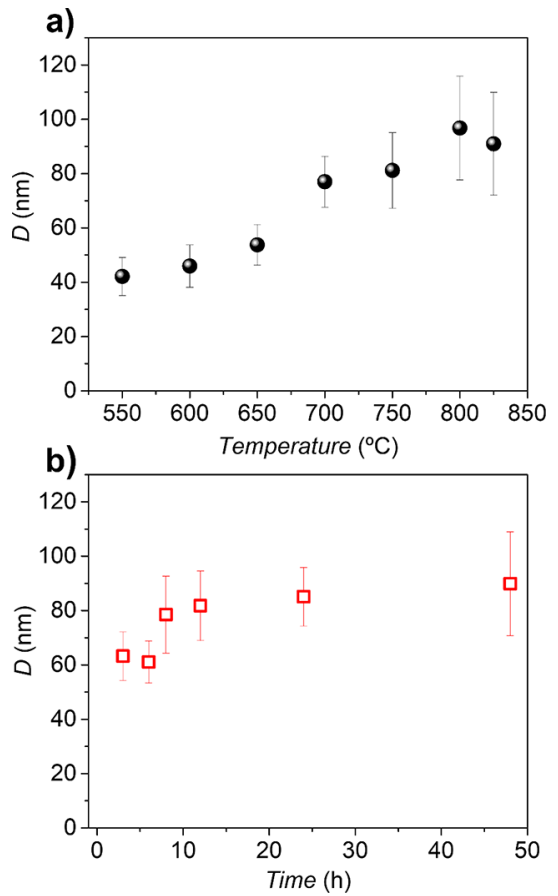

Figure 5. Diameter $(D)$ of $\alpha$ - $\mathrm{Fe}_{2} \mathrm{O}_{3} \mathrm{NWs}$ as function of annealing (a) temperature $\left(550-800{ }^{\circ} \mathrm{C}\right)$ and $(\mathrm{b})$ time $(3-48 \mathrm{~h})$.

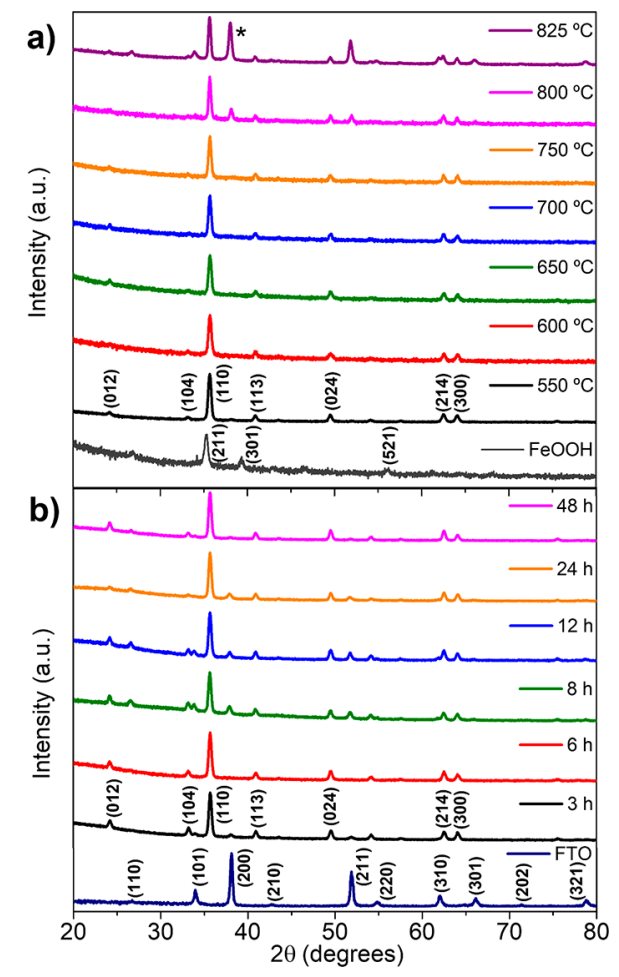

Figure 6. XRD spectra of $\alpha-\mathrm{Fe}_{2} \mathrm{O}_{3}$ samples annealed with different (a) temperature $\left(550-800{ }^{\circ} \mathrm{C}\right)$ and $(\mathrm{b})$ time $(3-48 \mathrm{~h})$. The $*$ symbol indicates the FTO peak.

increase of annealing temperature and time (insets of Figure S3a,b, respectively), ultimately improving the anisotropic conductivity. The increase of the anisotropic conductivity is also corroborated with the presence of the (110) preferential orientation for both sets of samples. The (110) reflection is indicative of growth along the [110] direction on the substrate,

referred by several authors to have anisotropic conductivity 4 orders magnitude higher than the direction perpendicular to it. ${ }^{11,12,53-55}$ However, a higher (104) contribution obtained for hematite NWs annealed with different time (Figure S3b) may be related to the lower $j$ obtained in general for this set of samples (Figure 1b).

For both sets of samples, a different broadening of the preferential (110) peak is also observed (Figure S3a,b). A small narrowing of the peak is observed as the annealing temperature and time increase, more evident in the set of different temperatures. The meaning of the XRD peak broadening is indicative of grain size refinement, but it is also related to other structural disorders, such as dislocations, microstrain, or local strain heterogeneity. ${ }^{35,50,56}$ From peak broadening analysis, crystallite size $\left(D_{\mathrm{XRD}}\right)$ and microstrain $(\varepsilon)$ were estimated, using the Williamson-Hall method: ${ }^{57}$

$$
w \cos \theta=\frac{k \lambda}{D_{\mathrm{XRD}}}+4 \varepsilon \sin \theta
$$

where $w$ is the full width at half-maximum (fwhm) of Bragg peaks, $\theta$ is the diffraction angle, $k$ is the Scherrer constant (0.94), and $\lambda$ is the incident X-ray wavelength (1.540593 $\AA$ ). From $w \cdot \cos (\theta)$ versus $4 \cdot \sin (\theta)$ plots, $D_{\mathrm{XRD}}$ and $\varepsilon$ were estimated from the intercept and slope, respectively (Figure S4).

Figure $7 \mathrm{a}, \mathrm{b}$ shows the results of $D_{\mathrm{XRD}}$ with annealing temperature and time and its relationship with $j$ (at $1.45 \mathrm{~mA}$. $\mathrm{cm}^{-2}$ ) and $D$ obtained from the SEM analysis. For samples at different temperatures, $D_{\mathrm{XRD}}($ and $D$ ) values remain almost constant up to $700{ }^{\circ} \mathrm{C}$ and increases from 750 up to $800{ }^{\circ} \mathrm{C}$, reaching a maximum value of $66 \mathrm{~nm}$ (Figure 7a). Samples with higher annealing temperatures show good quality of nanostructures presenting larger crystallites and fewer lattice defects, conferred by short annealing at high temperatures. $^{12,25,27}$ This ultimately leads to good photoresponses since less electron-hole recombination losses occur. ${ }^{50}$ Although the $825{ }^{\circ} \mathrm{C}$ photoanode presents a $j$ comparable to the $800{ }^{\circ} \mathrm{C}$ one, a lower $D_{\text {XRD }}$ was obtained, probably affected by the FTO deformation at higher temperatures. Increasing annealing time up to $24 \mathrm{~h}, D_{\text {XRD }}$ presents approximately the same dimensions (Figure $7 \mathrm{~b}$ ). In contrast, at $48 \mathrm{~h}$ a slight $D_{\mathrm{XRD}}$ increase (to $37 \mathrm{~nm}$ ) is observed in straight accordance with $j$ and $D$.

However, $\varepsilon<0.2 \%$ was obtained for almost all samples (Table S1). When $\varepsilon$ takes such low values, it is usually considered not significant for physical properties and can be overlooked. ${ }^{50,58,59}$ One exception is the $800{ }^{\circ} \mathrm{C}$ sample, with $\varepsilon$ $=0.22 \%$. The $\varepsilon$ parameter is correlated with the local strain nonhomogeneity due to lattice dislocations/distortions and grain surface relaxation, which can be caused when dopants such as $\mathrm{Sn}$ are incorporated into hematite structure by $\mathrm{Fe}$ substitution. $^{22,50,56}$ Although not significant $(\varepsilon<0.2 \%), \varepsilon$ also increases with increasing annealing temperature and time (Table S1). We believe that a surface relaxation, besides being caused by the increase of crystal size, is induced by the growing increment of Sn into hematite NWs, which could also justify the volume expansion of the unit cell, $V$ (see Table S1).

3.3.2. X-ray Absorption Fine Structure Snalysis. X-ray absorption near the edge structure (XANES) analysis allows the determination of the electronic structure of the photoelectrodes. ${ }^{36}$ The XANES results for samples with different annealing temperature and time were compared with the iron 

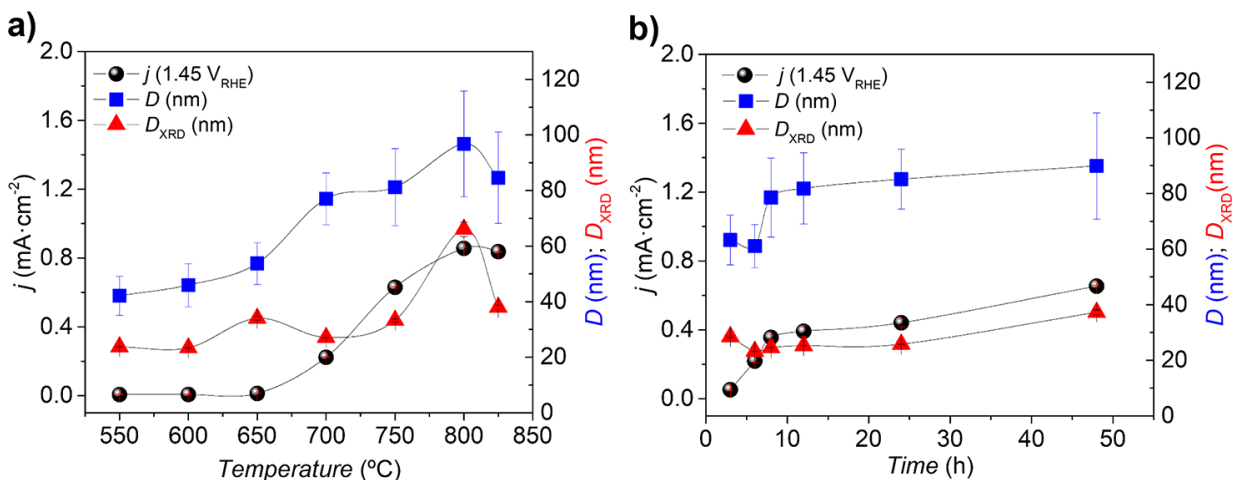

Figure 7. Results of current density (j), crystallite size $\left(D_{\text {XRD }}\right)$, and NWs diameter $(D)$ of $\alpha$ - $\mathrm{Fe}_{2} \mathrm{O}_{3}$ samples annealed with different (a) temperatures and (b) time.
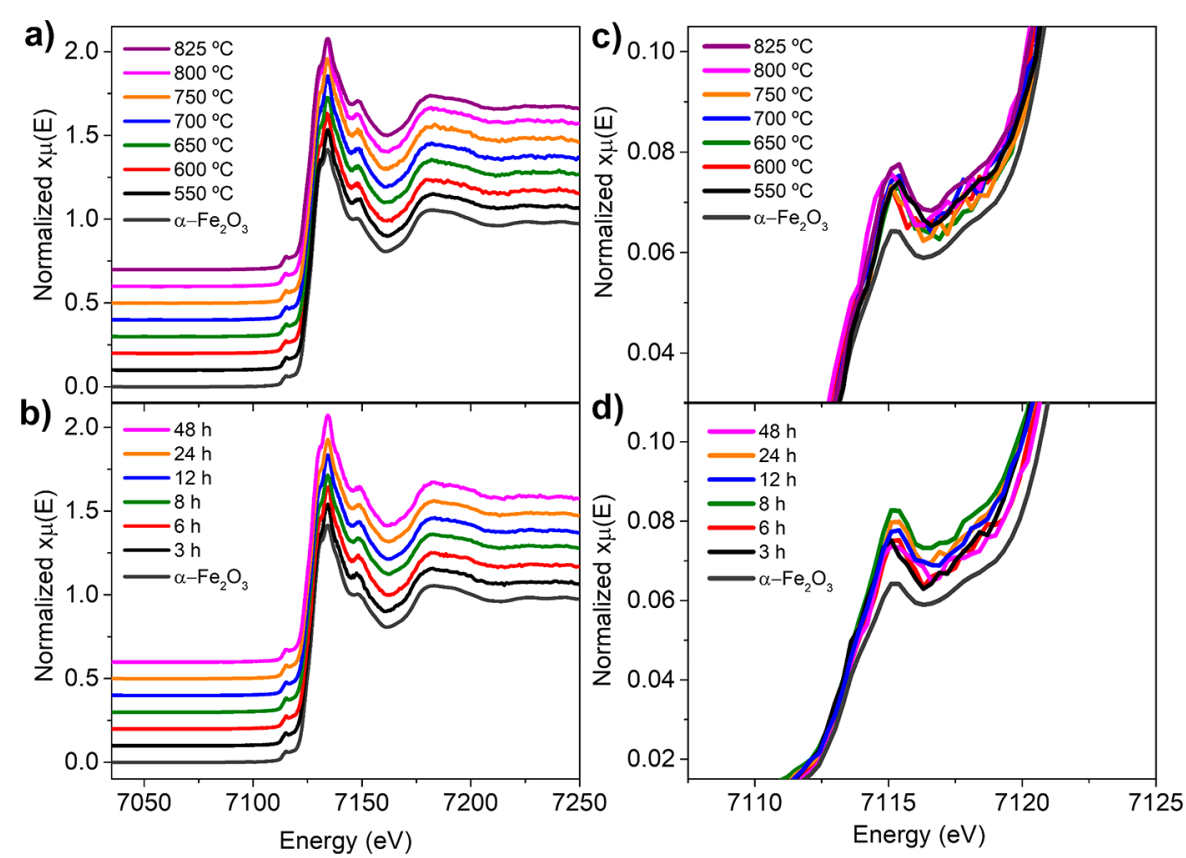

Figure 8. XANES spectra of hematite NWs with different annealing (a) temperatures and (b) times. Detail of the pre-edge peaks for hematite NWs with different annealing (c) temperatures and (d) times. All spectra are compared with the $\alpha-\mathrm{Fe}_{2} \mathrm{O}_{3}$ reference powder.

oxide references $\alpha$ - $\mathrm{Fe}_{2} \mathrm{O}_{3}, \gamma-\mathrm{Fe}_{2} \mathrm{O}_{3}$, and $\mathrm{Fe}_{3} \mathrm{O}_{4}$ (Figure S5). It was identified the typical hematite structure for all samples (pre-edge and edge peak features and energy positions correspond to the one of hematite reference) as can be seen in Figure 8a,b, respectively, for annealing temperature and time. The position of pre-edge peak center (known as centroid) and its intensity are key factors for the Fe oxidation state determination. In the literature, the $7115 \mathrm{eV}$ pre-edge peak is attributed to hematite and referred to as the quadrupole transition of $1 \mathrm{~s} \rightarrow 3 \mathrm{~d} .{ }^{60}$ Looking closely at the pre-edge peaks in Figure $8 \mathrm{c}, \mathrm{d}$, all the samples are aligned with the centroid position from the $\alpha-\mathrm{Fe}_{2} \mathrm{O}_{3}$ reference. ${ }^{60}$

Figure 9a,b shows the EXAFS spectra that allow the determination of the geometrical structure concerning the atoms around $\mathrm{Fe}^{36}$ The EXAFS spectra were obtained by the $k^{3}$-weight functions of the Fourier transforms of Fe $k$-edge. All the hematite photoanodes showed two peaks in the Fourier transforms of EXAFS functions, as usually reported in literature. $^{19,22,37,61}$

While the first peak $(0.6-2.0 \AA)$ is attributed to the nearest $\mathrm{Fe}-\mathrm{O}$ bond and commonly referred to the increase of ordering in the nanostructure, ${ }^{19,22,36,61}$ the second peak $(2.1-3.9 \AA)$ is related to the contribution from $\mathrm{Fe}-\mathrm{M}(\mathrm{M}=\mathrm{Fe}, \mathrm{Sn}, \mathrm{Ti}$, or other dopant) and $\mathrm{Fe}-\mathrm{O}$ bonds at a greater distance. ${ }^{19,22}$ Furthermore, the intensity of this peak gives a perception of dopant environment around Fe atoms.

For both sets of samples with different annealing temperature and time (Figure 9a,b), the peaks have higher intensities than the $\alpha-\mathrm{Fe}_{2} \mathrm{O}_{3}$ powder reference, which indicates an enhanced bond ordering for the NWs grown on the FTO surface. ${ }^{19}$ A slight increase in the first peak is noticed for the sample with annealing conditions of $800{ }^{\circ} \mathrm{C}$ and $48 \mathrm{~h}$ (Figures $9 a, b$ and $S 6 a, b)$. This indicates an enhancement of the structural order with the annealing temperature and time.

The second peak also increases with the annealing temperature, being more evident in the $800{ }^{\circ} \mathrm{C}$ photoelectrode (Figures 9a and S6a). This peak is ascribed to the backscattering of $\mathrm{Sn}$ atoms that are incorporated into hematite lattice by diffusion from FTO substrate with annealing temperature. The higher the Sn concentration, the stronger the atomic backscattering and thus more intense the second peak. $^{19,22,61}$ For samples with different annealing times, no 


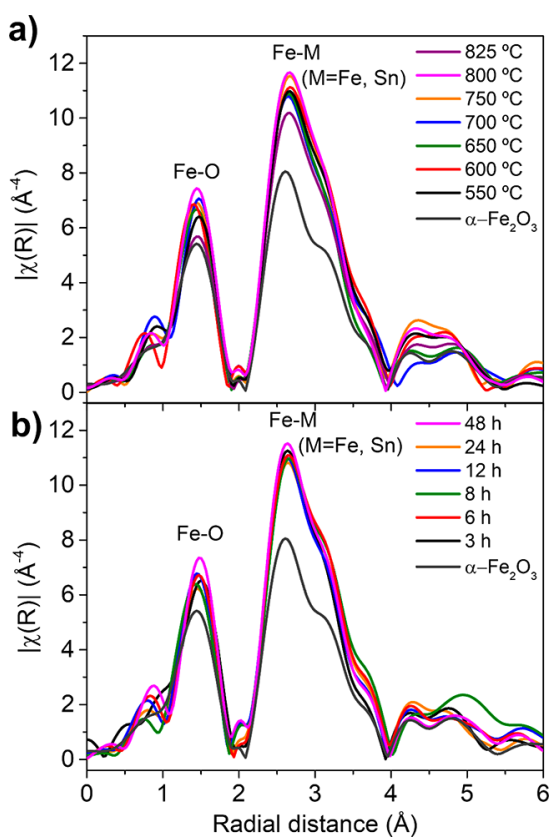

Figure 9. $k^{3}$-weighted Fourier transforms of Fe K-edge EXAFS functions for hematite NWs with different annealing (a) temperatures and (b) times.

significant differences were observed, however the slight increase in the second peak for the $48 \mathrm{~h}$ sample also indicates a $\mathrm{Sn}$ evolution through the hematite nanostructure (Figures $9 \mathrm{~b}$ and $\mathrm{S} 6 \mathrm{~b}$ ).

In the Fourier-transformed data, the increase in the intensities of the first and the second peaks is directly correlated with decreasing the Debye-Waller factor $\left(\sigma^{2}\right)$, which is related to the structural disorder. ${ }^{36}$ By fitting the EXAFS data, $\sigma^{2}$ was calculated (Table S1). $\sigma^{2}$ decreases as the annealing temperature increases, confirming the good ordering of the atomic structure and quality of the samples. This improvement of bond ordering is also in straight accordance with XRD results in which an increase of crystalline structure occurs for higher annealing temperature (Figure 7a). It is more evident at $800{ }^{\circ} \mathrm{C}$ in accordance with $D_{\text {XRD }}$ analysis. Furthermore, $\sigma^{2}$ for all photoanodes is smaller than that for the reference $\alpha-\mathrm{Fe}_{2} \mathrm{O}_{3}$ confirming higher ordering of the NW structures nucleated upon FTO. ${ }^{21,36}$ However, $\sigma^{2}$ in general presents higher values for the set of annealing times. This behavior is probably caused by some FTO deformation with prolonged annealing time.

3.3.3. RBS Analysis. RBS is a very sensitive structural analysis technique that can be used to determine the distribution in depth of chemical elements. ${ }^{46,62-64}$ In this work, it revealed to be crucial to evaluate the $\mathrm{Sn}$ diffusion induced by annealing temperature and its influence in our photoanodes photoresponse. While XPS analysis gives atomic percentage information with a resolution of $5-10 \mathrm{~nm}$ in depth, RBS is a powerful technique that allows the atomic determination along photoanodes' total layers (on the order of the photoanodes total thickness and from the surface).

In order to determine the atomic Sn percentage along the photoanodes layers, the sample annealed at $800{ }^{\circ} \mathrm{C}$ with higher photocurrent efficiency $(j)$ was analyzed using RBS and compared with samples with lower efficiencies (550 and 600 ${ }^{\circ} \mathrm{C}$ ). Figure 10a,b shows respectively the RBS random spectra of the FTO substrate and the referred samples where the 2 $\mathrm{MeV} \mathrm{He}^{+} \alpha$ particles are impinged at the sample with an incident angle $(\theta)$ of $5^{\circ}$ with respect to the sample normal and are collected in a scattering angle $\theta_{2}$ of $-140^{\circ}$. Comparing RBS random spectra for the FTO substrates in two different sample positions (P1 and P2 in Figure 10a) allows concluding similar composition and thickness.

According to the random spectrum of the calibration sample (not shown), the $\mathrm{Sn}$ and Fe elements were identified at the surface for the studied samples. The $\mathrm{Sn}$ and Fe barriers are identified in Figure $10 \mathrm{~b}$ as vertical arrows around channels 500 $[E=1710 \mathrm{keV}]$ and $450[E=1573 \mathrm{keV}]$, respectively.

In the simple cases, considering for example a nonrough $\mathrm{Fe}$ film with $\mathrm{Sn}$ at the surface, the chemical composition is straightforward as the ratio between the signals of the elements in the spectra and its scattering cross sections calculated for the backscattering angle and beam alpha particles energy (2000 $\mathrm{keV}$ ). Not only the percent Sn but also other quantities, such as layer thickness, chemical composition, roughness, and occupancy percentage of voids, were derived via RBS simulation. ${ }^{45,46,63,64}$

The total thickness of the Sn containing region (depicted in Figure 10b) was simulated using the NDF code $\mathrm{e}^{45,46}$ as having $580 \mathrm{~nm}$, which agrees well with the FTO thickness taken from SEM images $\left(L_{\text {FTO mean }} \sim 525 \pm 32 \mathrm{~nm}\right)$. However, the Fe signal suggests a total thickness of a region containing iron of around $200 \mathrm{~nm}$. Moreover, measurements using different incident angles ( 20 and $30^{\circ}$ not shown) indicate that both $\mathrm{Fe}$ and $\mathrm{Sn}$ are already present at the surface. The shape of the $\mathrm{Sn}$
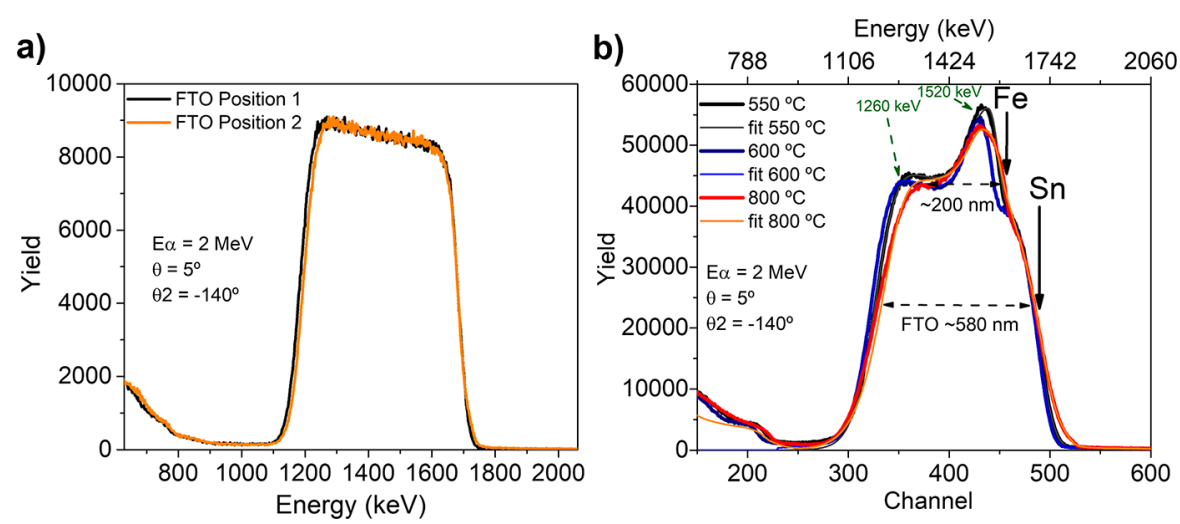

Figure 10. RBS spectra of (a) FTO substrate and (b) $\alpha-\mathrm{Fe}_{2} \mathrm{O}_{3} \mathrm{NWs}$ annealed at 550, 600, and $800{ }^{\circ} \mathrm{C}$ and respective fits. 
and $\mathrm{Fe}$ signals between 1260 and $1520 \mathrm{keV}$ suggests a roughness-diffusion mechanism according to the analysis of the NDF code. $^{63,64}$ In this mechanism, $\mathrm{Sn}$ atoms are moving toward the surface (deduced by the decrease of the Sn yield in that energy range with increasing annealing temperature), and the Fe yield is increasing smoothly, suggesting a slightly increase of roughness as the annealing temperature increases. Furthermore, the shape of the Sn signal changes from a sharp barrier-like spectra to a more tilted barrier if RBS random spectra of FTO (Figure 10a) is compared with the random spectra of annealed structures. Two hypothetical effects can produce such tilting: decreasing of detector resolution and roughness increasing. The first hypothesis is discarded due to measurement $(10 \mathrm{keV})$ of the detector energy resolution.

Through the random spectra fitting, parameters such as percent $\mathrm{Sn}$ along the photoanodes thickness were determined for the samples annealed at 550,600 , and $800{ }^{\circ} \mathrm{C}$. It was found that the sample with $800{ }^{\circ} \mathrm{C}$ has an increase of percent $\mathrm{Sn}$ along the NWs depth, reaching a maximum value of $\sim 8 \%$ at the surface and distributed over a layer of $\sim 162 \mathrm{~nm}$. A larger amount of $\mathrm{Sn}$ is usually associated with the increase of photoactivity, due to the increase of donor density and thus the electrical conductivity. ${ }^{12,13,17,19,21,24,25}$ Therefore, this kind of photoelectrode shows improved electrical conductivity properties that ultimately lead to higher $j$. Similar percent $S n$ results under the same conditions have been reported by XPS analysis. ${ }^{12}$ However, the $550{ }^{\circ} \mathrm{C}$ photoelectrode presents only $0.6 \% \mathrm{Sn}$ at the surface, distributed alongside a layer of $\sim 198$ $\mathrm{nm}$. This smaller percent $\mathrm{Sn}$ justifies the reduced $j$ obtained for the sample with $550{ }^{\circ} \mathrm{C}$ and is usually attributed to the low conductivity of bare hematite. ${ }^{6,7,12}$ Figure 11a shows the Sn distribution along the NWs layers, i.e., the product between
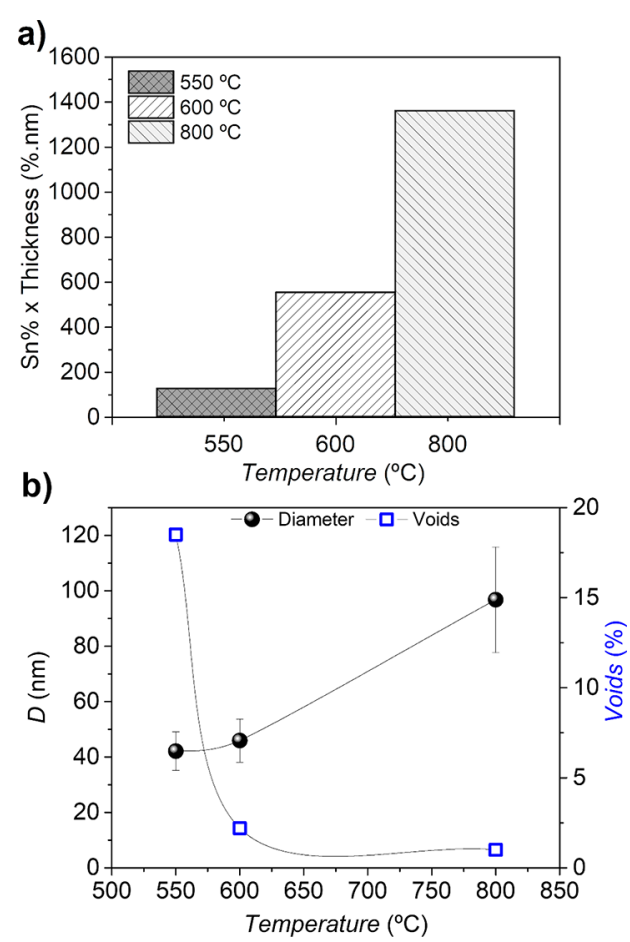

Figure 11. (a) Product between percent Sn and simulated thickness determined by RBS fits for samples with 550,600 , and $800{ }^{\circ} \mathrm{C}$. (b) Voids (\%) (from first layer $\sim 100-200 \mathrm{~nm}$ ) determined by RBS fits for samples with 550,600 , and $800{ }^{\circ} \mathrm{C}$, in comparison with NWs diameter $(D)$. percent $\mathrm{Sn}$ and simulated thickness, where simulated thickness varies from 100 to $200 \mathrm{~nm}$ for $550-800{ }^{\circ} \mathrm{C}$ and percent $\mathrm{Sn}$ varies from 0.6 to $8 \%$. In fact, the photoelectrode annealed at $800{ }^{\circ} \mathrm{C}$ shows $\sim 10$ times more $\mathrm{Sn}$ than the one annealed at $550{ }^{\circ} \mathrm{C}$. The presence of a higher percent $\mathrm{Sn}$, not only at the surface, but homogeneously distributed along the NWs, allows the enhancement of the charge separation efficiency and transport along the photoelectrodes, leading to higher $j .{ }^{12,17,19,24}$ Therefore, $j$ is directly related with Sn doping through FTO diffusion. Additionally, higher microstrain $(\varepsilon)$ and volume expansion of the unit cell $(V)$ observed for the 800 ${ }^{\circ} \mathrm{C}$ photoelectrode (section 3.3.1) can now be confirmed in good correlation with higher $\mathrm{Sn}$ diffusion at this temperature.

The simulations of the RBS spectra reveal also a decrease of the voids fraction as $D$ increases with annealing temperature (Figure $11 \mathrm{~b}$ ). In fact, as $D$ increases, the empty space between NWs will decrease, and thus the voids fraction naturally should decrease.

3.4. Optical Characterization. Figure 12a,b shows respectively the absorption spectra for the photoelectrodes

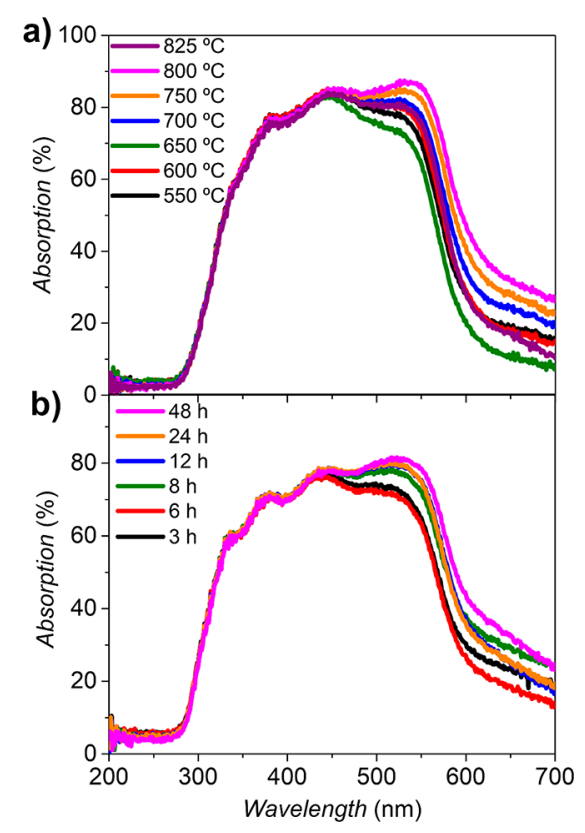

Figure 12. UV-vis absorption spectra of hematite NWs with different annealing (a) temperatures and (b) times.

annealed with different temperature and time. The maximum absorption peak was observed at $\sim 440 \mathrm{~nm}$ for samples annealed at up to $700{ }^{\circ} \mathrm{C}$ and up to $8 \mathrm{~h}$. Above these temperature and time conditions, the maximum absorption shifts to higher wavelengths (red-shift) in the range of 531$540 \mathrm{~nm}$ (see also Table S2), which corresponds to samples with higher $j$, NWs diameter $(D)$, and Sn incorporation (which enhances the hematite conductivity). ${ }^{22,25,65}$

Usually, hematite thin films display an intense absorption peak around $400 \mathrm{~nm},{ }^{4,19,40}$ whereas mesoporous nanostructures show two different absorptions peaks at 375 and 535 $\mathrm{nm} .^{66}$ A transition in the absorption coefficient $\alpha=535 \mathrm{~nm}$ has been previously attributed to spin-forbidden ligand field $\left({ }^{6} \mathrm{~A}_{1}\right.$ $\rightarrow{ }^{4} \mathrm{E}$ ) transition and is related to changes in the nanostructures morphology. ${ }^{25,65}$ The maximum absorption shift was also reported for mesoporous nanostructures, and it is governed by the morphology (particle size and shape), 

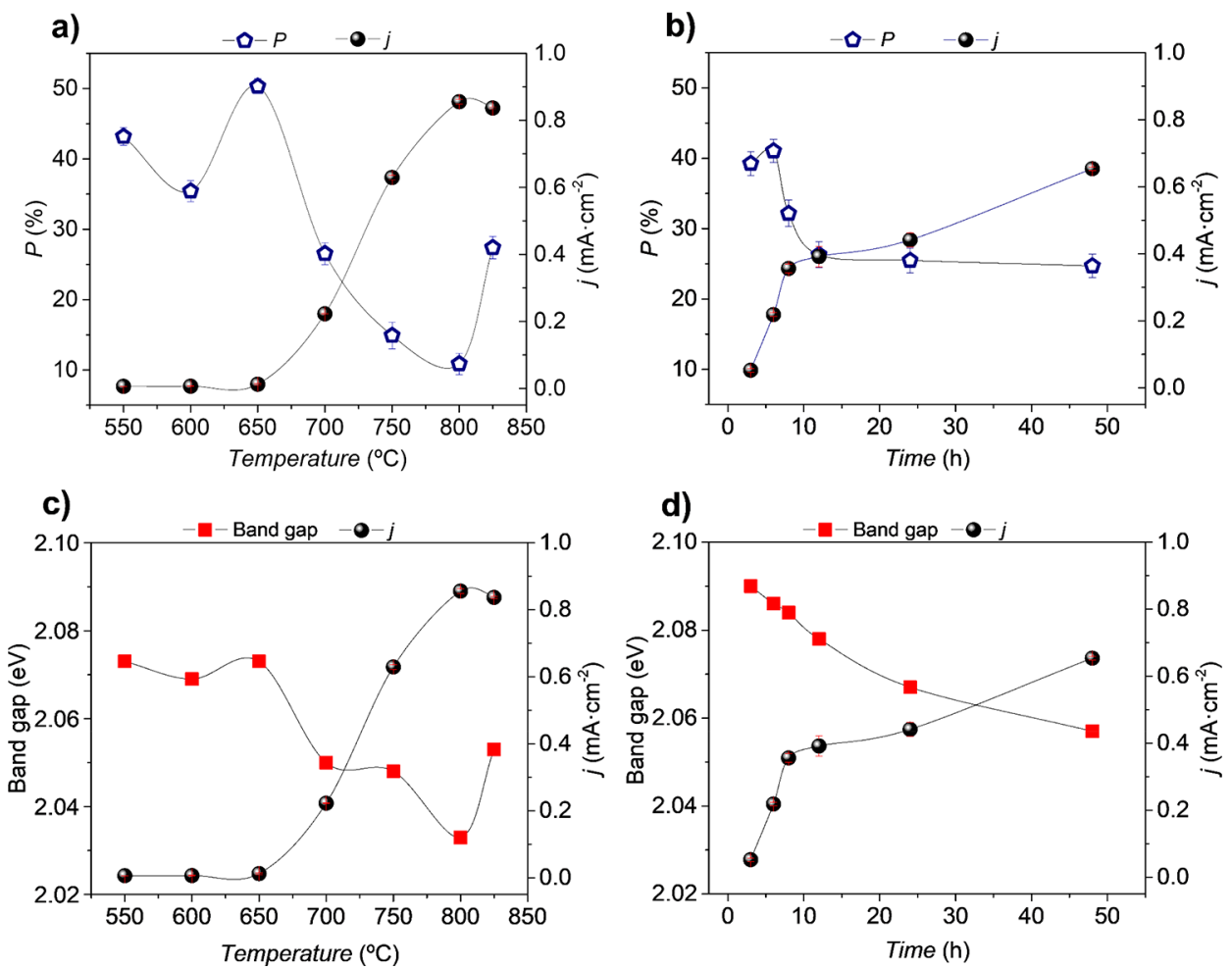

Figure 13. Porosity $(P)$, calculated from SEM analysis of NWs thickness $(L)$ and thickness from spectrophotometric analysis $\left(L_{\mathrm{UV}-\mathrm{vis}}\right)$, for samples with different (a) temperature and (b) time, comparing with photocurrent density $(j)$. Optical band gap for hematite NWs with different annealing (c) temperatures and (d) times.

annealing temperature, or use of dopants. For example, a redshift was observed with higher particle size and Sn incorporation. $^{22,25}$ As could be verified by EXAFS and RBS analyses, the presence of $S n$ was confirmed in those samples with higher absorption, leading to increased photocurrent.

It is usually described that thicker samples absorb more visible light, ${ }^{50}$ but the analyzed samples do not show a significant difference concerning the thickness $L$ (analyzed by SEM; Figure S2 and Table S2). Thus, the observed differences in the absorption should be due to NWs diameter $(D)$ and/or porosity features. Considering the higher absorption peak at $\lambda$ $=531 \mathrm{~nm}$, near to the known absorption band at $18690 \mathrm{~cm}^{-1}$ described by Marusak et al. ${ }^{65}$ and assigned to ligand field transitions [which corresponds to an absorption coefficient $(\alpha)$ of $\left.(126.46 \mathrm{~nm})^{-1}\right]$, the thickness $\left(L_{\mathrm{UV}-\mathrm{vis}}\right)$ of the NWs was estimated:

$$
-\alpha L_{\mathrm{UV}-\mathrm{vis}}=\ln (1-\text { Absorbance })
$$

and compared with the thickness $L$ from SEM analysis (Figure S7).

The porosity $P$ of the photoelectrodes can be determined from $L$ and $L_{\mathrm{UV}-\mathrm{vis}}$ :

$$
P=\frac{V_{\text {bulk }}-V_{\text {oxide }}}{V_{\text {bulk }}} \times 100 \%=\frac{L-L_{\mathrm{UV}-\text { vis }}}{L} \times 100 \%
$$

where $V_{\text {bulk }}$ is the volume of bulk material (NWs plus pores) and $V_{\text {oxide }}$ is the volume of hematite NWs. ${ }^{67}$

The porosity $(P)$ of hematite NWs is shown in Figure 13a,b. The results show an inverse relation between porosity and $j$, as annealing temperature and time increase. $P$ decreases from $\sim 43$ to $11 \%$ as the annealing temperature increases from 550 to $800{ }^{\circ} \mathrm{C}$ (Figure 13a); in contrast, the porosity decreases from $\sim 40$ to $25 \%$ as the annealing time increases from 3 to 48 $\mathrm{h}$ (Figure 13b). It should be emphasized the same decreasing trend obtained by RBS fits regarding the voids fraction (Figure $11 \mathrm{~b})$, in strong correlation with the porosity results.

Moreover, the porosity average $P_{\text {mean }} \sim 33 \%$ using all $P$ values (temperature and time) obtained in Figure 13a,b. However, if we analyze a SEM cross-section image of the NWs (Figure 14), delimit a rectangular area that represents the bulk area $\left(A_{\text {bulk }}=1088 \mu \mathrm{m}^{2}\right)$, and delimit the area of the NWs $\left(A_{\text {oxide }}=732 \mu \mathrm{m}^{2}\right)$, then it is possible to estimate the porosity using eq 6; the porosity obtained using this approach is $P \sim$ $32.7 \%$, which corroborates with the effective porosity confirming the above results.

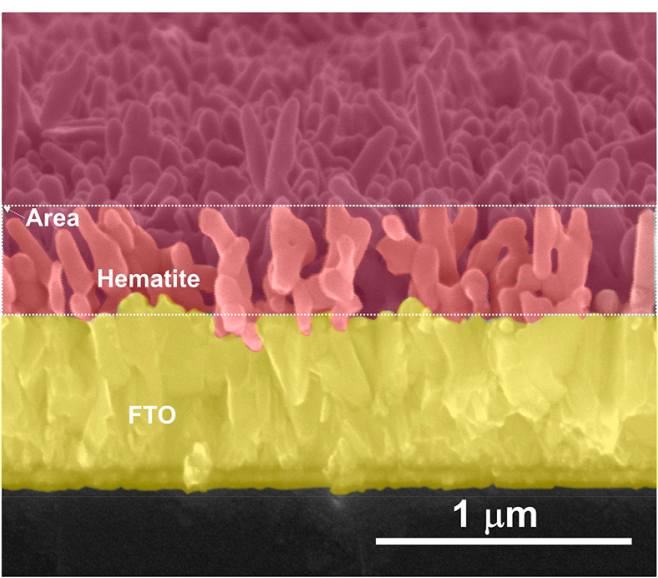

Figure 14. SEM cross-sectional image of hematite NWs with delimited bulk (dashed white line) and NWs (reddish) areas. 
Usually in the literature, porous structures (higher $P$ ) indicate higher photoactive surface areas of the photoelectrodes. ${ }^{8}$ Here, a porosity opposite trend with $j$ occurs. $P$ decreases with the increase of $j$ for both groups of samples (Figure 13a,b). However, the photoresponse is not only determined by the morphology; other key factors influence the $j$ behavior in our samples such as the structure crystallinity and Sn "unintentional" doping and conductivity: (i) Morphology: As annealing temperature and time increase, the NWs diameter (D) increases, leading to a decrease of the empty space between NWs (and thus the porosity decreases). (ii) Structure-crystallinity: As annealing temperature and time increase, the crystallite size $\left(D_{\mathrm{XRD}}\right)$ also increases; the quality of the photoelectrodes at the level of crystalline order and lattice arrangement is improved. (iii) Sn "unintentional" doping and conductivity: As annealing temperature and time increase, the Sn diffusion from FTO into hematite leads to the increase of conductivity and the photocurrent increases.

Therefore, the photocurrent response of the hematite NWs photoelectrodes is the balance of these three factors. What we see here is that all three factors described above are more important than the impact of the surface area factor (porosity). The band gap of the hematite photoelectrodes was obtained from the Tauc plots: ${ }^{68}$

$$
(\alpha h \nu)=A\left(h \nu-E_{\mathrm{g}}\right)^{n}
$$

where $h \nu$ is the incident photon energy $(\mathrm{eV}), E_{\mathrm{g}}$ is the optical band gap energy $(\mathrm{eV})$, and $A$ and $n$ are constants dependent on the electronic transition: $n=2$ for direct and $n=1 / 2$ for indirect allowed transitions. ${ }^{29,50}$ The determined band gap values calculated for $n=1 / 2$ agree with those reported in the literature. ${ }^{6,7,25}$ The band gap decreases with the increase of annealing temperature and time (Figure 13c,d, and Table S3) as the $j$ increases. In fact, with the increases of annealing temperature and time, we have higher Sn diffusion that leads to the enhancement of the photoelectrodes' conductivity. The porosity and band gap evolution for both sets of samples (for higher annealing temperature and time) revealed a similar decreasing trend (Figure $13 \mathrm{a}-\mathrm{d}$ ). As referred to above, this decrease was mainly attributed to particle size effects, crystalline order, and changes in lattice parameters, usually induced by Sn doping, ${ }^{19,25}$ as observed in EXAFS studies and confirmed by RBS analysis.

\section{CONCLUSIONS}

In this work, the impact of annealing temperature and time on the photoperformance of hematite nanostructured photoelectrodes was thoroughly investigated. Higher photocurrent densities typical of bare hematite were observed for photoelectrodes annealed with a two-step approach, at $550{ }^{\circ} \mathrm{C}$ for 2 $\mathrm{h}$ followed by $20 \mathrm{~min}$ at $800{ }^{\circ} \mathrm{C}\left(\sim 0.9 \mathrm{~mA} \cdot \mathrm{cm}^{-2}\right)$ and under a one-step approach at $600{ }^{\circ} \mathrm{C}$ during $48 \mathrm{~h}\left(\sim 0.7 \mathrm{~mA} \cdot \mathrm{cm}^{-2}\right)$. Under the two-step annealing approach, the photocurrent increased with the increase of the temperature. This was ascribed to the improvement of structural crystalline order and the increase of the Sn diffused from the FTO substrate layer within the hematite crystalline lattice. The hematite NWs showed a preferential crystal orientation along the (110) plane for both annealing schemes (temperature and time) that confers improved conductivity ultimately leading to improved photocurrents. However, the photoelectrodes annealed with different time showed a more intense (104) crystalline reflection peak, indicating limited conductivity that results in lower photocurrents. XANES studies confirmed the presence of pure hematite crystallographic phase, while EXAFS confirmed the Sn doping, which was corroborated by RBS analysis. The sample with two-step annealing at $800{ }^{\circ} \mathrm{C}$ displayed the highest photocurrent, related to an improved donor density and electronic conductivity. Accordingly, the RBS analysis showed that the in-depth percent Sn profile for this sample was ca. 10 times higher when compared with that of the sample annealed at $550{ }^{\circ} \mathrm{C}$ (with the lowest photocurrent). Additionally, the cross-sectional views allowed estimation of the thickness of the NWs photoelectrodes. Combined with optical UV-vis absorption spectra, it was estimated the porosity of the hematite photoelectrodes active and effective layer. Furthermore, the photoelectrodes' porosity and photocurrent are inversely related for both annealing conditions (temperature and time). The differences observed in absorption spectra (red-shifted), caused by the increase of NWs diameter with higher annealing temperature and time, are clearly reflected in the decrease in porosity. In addition, the porosity shows decreasing performance similar to the voids fraction obtained from the RBS simulation. The porosity also revealed a similar trend with the band gap, assigned to the $\mathrm{Sn}$ diffusion that affects the absorption. With this work, the underlying insights of the annealing conditions, temperature and time, and its impact in the performance of hematite NWs were unveiled, important for future improvement of hematite photoelectrodes.

\section{ASSOCIATED CONTENT}

\section{Supporting Information}

The Supporting Information is available free of charge at https://pubs.acs.org/doi/10.1021/acs.jpcc.0c01259.

$j-V$ curves, NWs thickness from SEM analysis, XRD refinement plots, Williamson-Hall fits, XANES spectra of Fe-oxide references, EXAFS results, NWs thickness from SEM and UV-vis analysis, lattice parameters from XRD refinement, structural parameters from EXAFS analysis, and optical bandgaps (PDF)

\section{AUTHOR INFORMATION}

\section{Corresponding Author}

João Pedro Araújo - IFIMUP - Institute of Physics for Advanced Materials, Nanotechnology and Photonics of University of Porto and Departamento de Física e Astronomia, Faculdade de Cîncias da Universidade do Porto, 4169-007 Porto, Portugal; Email: jearaujo@fc.up.pt

\section{Authors}

Paula Quitério - IFIMUP - Institute of Physics for Advanced Materials, Nanotechnology and Photonics of University of Porto and Departamento de Fisica e Astronomia, Faculdade de Ciências da Universidade do Porto, 4169-007 Porto, Portugal; (1) orcid.org/0000-0001-8635-3568

Arlete Apolinário - IFIMUP - Institute of Physics for Advanced Materials, Nanotechnology and Photonics of University of Porto and Departamento de Fisica e Astronomia, Faculdade de Ciências da Universidade do Porto, 4169-007 Porto, Portugal; (1) orcid.org/0000-0001-5891-1948

David Navas - ICMM-CSIC - Instituto de Ciencia de Materiales de Madrid, 28049 Madrid, Spain 
Sérgio Magalhães - IPFN - Instituto de Plasmas e Fusão Nuclear, Campus Tecnologico e Nuclear, Instituto Superior Tecnico, Universidade de Lisboa, Bobadela LRS 2695-066, Portugal

Eduardo Alves - IPFN - Instituto de Plasmas e Fusão Nuclear, Campus Tecnologico e Nuclear, Instituto Superior Técnico, Universidade de Lisboa, Bobadela LRS 2695-066, Portugal

Adélio Mendes - LEPABE - Faculdade de Engenharia, Universidade do Porto, 4200-465 Porto, Portugal; (1) orcid.org/0000-0003-2472-3265

Célia Tavares Sousa - IFIMUP - Institute of Physics for Advanced Materials, Nanotechnology and Photonics of University of Porto and Departamento de Fisica e Astronomia, Faculdade de Ciencias da Universidade do Porto, 4169-007 Porto, Portugal; ○ orcid.org/0000-0003-2879-0051

Complete contact information is available at: https://pubs.acs.org/10.1021/acs.jpcc.0c01259

\section{Author Contributions}

The manuscript was written through contributions of all authors. All authors have given approval to the final version of the manuscript.

\section{Notes}

The authors declare no competing financial interest.

\section{ACKNOWLEDGMENTS}

This work was supported by FCT - Fundação para a Ciência e a Tecnologia, North Portugal Regional Operational Programme (NORTE 2020), under the Portugal 2020 Partnership Agreement, through the European Regional Development Fund (ERDF) [Network of Extreme Conditions LaboratoriesNECL, Project Ref. NORTE-01-0145-FEDER-022096; "LEPABE-2-ECO-INNOVATION”- NORTE- 01-0145-FEDER000005], through COMPETE2020, Operational Programme for Competitiveness and Internationalisation (OPCI) [POCI01-0141-FEDER-032527; POCI-01-0145-FEDER-031302; MIT-EXPL/IRA/0012/2017; PTDC/CTM-CTM/28676/ 2017; POCI-01-0145-FEDER-032257; POCI-01-0145FEDER-016387; POCI-01-0145-FEDER-030760; POCI-010145-FEDER-030510], European Union's Horizon 2020 research and innovation program under the Marie Sklodowska-Curie Grant Agreement No. 734801, Strategic Funding contract UID/FIS/50010/2019 and projects UID/EQU/ 00511/2019 - Laboratory for Process Engineering, Environment, Biotechnology and Energy - LEPABE, UID/NAN/ 50024/2019 and UIDB/04968/2020 - Institute of Physics for Advanced Materials, Nanotechnology and Photonics IFIMUP. P.Q., A.A., and C.S. acknowledge FCT respectively for grants SFRH/BD/110698/2015, SFRH/BPD/87430/2012 and IF/01159/2015. D.N. acknowledges the Spanish Ministry for Science, Innovation and Universities for funding through the "Ramón y Cajal" program RYC-2017-22820.

\section{REFERENCES}

(1) Grätzel, M. Photoelectrochemical Cells. Nature 2001, 414, 338344.

(2) Ardo, S.; Fernandez Rivas, D.; Modestino, M. A.; Schulze Greiving, V.; Abdi, F. F.; Alarcon Llado, E.; Artero, V.; Ayers, K.; Battaglia, C.; Becker, J.-P.; et al. Pathways to Electrochemical SolarHydrogen Technologies. Energy Environ. Sci. 2018, 11, 2768-2783.

(3) Murphy, A. B.; Barnes, P. R. F.; Randeniya, L. K.; Plumb, I. C.; Grey, I. E.; Horne, M. D.; Glasscock, J. A. Efficiency of Solar Water
Splitting Using Semiconductor Electrodes. Int. J. Hydrogen Energy 2006, 31, 1999-2017.

(4) Dias, P.; Vilanova, A.; Lopes, T.; Andrade, L.; Mendes, A. Extremely Stable Bare Hematite Photoanode for Solar Water Splitting. Nano Energy 2016, 23, 70-79.

(5) Xie, J.; Yang, P.; Liang, X.; Xiong, J. Self-Improvement of $\mathrm{Ti}: \mathrm{Fe}_{2} \mathrm{O}_{3}$ Photoanodes: Photoelectrocatalysis Improvement after Long-Term Stability Testing in Alkaline Electrolyte. ACS Appl. Energy Mater. 2018, 1, 2769-2775.

(6) Sivula, K.; Le Formal, F.; Grätzel, M. Solar Water Splitting: Progress Using Hematite $\left(\alpha-\mathrm{Fe}_{2} \mathrm{O}_{3}\right)$ Photoelectrodes. ChemSusChem 2011, 4, 432-449.

(7) Tamirat, A. G.; Rick, J.; Dubale, A. A.; Su, W.-N.; Hwang, B.-J. Using Hematite for Photoelectrochemical Water Splitting: A Review of Current Progress and Challenges. Nanoscale Horiz. 2016, 1, 243267.

(8) van de Krol, R., Grätzel, M., Eds. Photoelectrochemical Hydrogen Production; Springer US, 2012; Vol. 102.

(9) Morin, F. J. Electrical Properties of $\left(\mathrm{Fe}_{2} \mathrm{O}_{3}\right.$ and $\mathrm{Fe}_{2} \mathrm{O}_{3}$ Containing Titanium. Phys. Rev. 1951, 83, 1005-1010.

(10) Morin, F. J. Electrical Properties of $\alpha-\mathrm{Fe}_{2} \mathrm{O}_{3}$. Phys. Rev. 1954, 93, 1195-1199.

(11) Kment, S.; Schmuki, P.; Hubicka, Z.; Machala, L.; Kirchgeorg, R.; Liu, N.; Wang, L.; Lee, K.; Olejnicek, J.; Cada, M.; et al. Photoanodes with Fully Controllable Texture: The Enhanced Water Splitting Efficiency of Thin Hematite Films Exhibiting Solely (110) Crystal Orientation. ACS Nano 2015, 9, 7113-7123.

(12) Ling, Y.; Wang, G.; Wheeler, D. A.; Zhang, J. Z.; Li, Y. SnDoped Hematite Nanostructures for Photoelectrochemical Water Splitting. Nano Lett. 2011, 11, 2119-2125.

(13) Morrish, R.; Rahman, M.; MacElroy, J. M. D.; Wolden, C. A. Activation of Hematite Nanorod Arrays for Photoelectrochemical Water Splitting. ChemSusChem 2011, 4, 474-479.

(14) Sun, H.; Deng, J.; Qiu, L.; Fang, X.; Peng, H. Recent Progress in Solar Cells Based on One-Dimensional Nanomaterials. Energy Environ. Sci. 2015, 8, 1139-1159.

(15) Vayssieres, L.; Sathe, C.; Butorin, S. M.; Shuh, D. K.; Nordgren, J.; Guo, J. One-Dimensional Quantum-Confinement Effect in $\alpha$ $\mathrm{Fe}_{2} \mathrm{O}_{3}$ Ultrafine Nanorod Arrays. Adv. Mater. 2005, 17, 2320-2323.

(16) Vayssieres, L.; Beermann, N.; Lindquist, S.-E.; Hagfeldt, A. Controlled Aqueous Chemical Growth of Oriented Three-Dimensional Crystalline Nanorod Arrays: Application to Iron(III) Oxides. Chem. Mater. 2001, 13, 233-235.

(17) Kim, J. Y.; Magesh, G.; Youn, D. H.; Jang, J.-W.; Kubota, J.; Domen, K.; Lee, J. S. Single-Crystalline, Wormlike Hematite Photoanodes for Efficient Solar Water Splitting. Sci. Rep. 2013, 3, 2681.

(18) Jeon, T. H.; Moon, G.-h.; Park, H.; Choi, W. Ultra-Efficient and Durable Photoelectrochemical Water Oxidation Using Elaborately Designed Hematite Nanorod Arrays. Nano Energy 2017, 39, 211218.

(19) Shinde, P. S.; Choi, S. H.; Kim, Y.; Ryu, J.; Jang, J. S. Onset Potential Behavior in $\alpha-\mathrm{Fe}_{2} \mathrm{O}_{3}$ Photoanodes: The Influence of Surface and Diffusion Sn Doping on the Surface States. Phys. Chem. Chem. Phys. 2016, 18, 2495-2509.

(20) Yang, T.-Y.; Kang, H.-Y.; Jin, K.; Park, S.; Lee, J.-H.; Sim, U.; Jeong, H.-Y.; Joo, Y.-C.; Nam, K. T. An Iron Oxide Photoanode with Hierarchical Nanostructure for Efficient Water Oxidation. J. Mater. Chem. A 2014, 2, 2297-2305.

(21) Subramanian, A.; Gracia-Espino, E.; Annamalai, A.; Lee, H. H.; Lee, S. Y.; Choi, S. H.; Jang, J. S. Effect of Tetravalent Dopants on Hematite Nanostructure for Enhanced Photoelectrochemical Water Splitting. Appl. Surf. Sci. 2018, 427, 1203-1212.

(22) Annamalai, A.; Lee, H. H.; Choi, S. H.; Lee, S. Y.; GraciaEspino, E.; Subramanian, A.; Park, J.; Kong, K.-j.; Jang, J. S. Sn/Be Sequentially Co-Doped Hematite Photoanodes for Enhanced Photoelectrochemical Water Oxidation: Effect of $\mathrm{Be}^{2+}$ as Co-Dopant. Sci. Rep. 2016, 6, 23183. 
(23) Shavorskiy, A.; Ye, X.; Karslıoğlu, O.; Poletayev, A. D.; Hartl, M.; Zegkinoglou, I.; Trotochaud, L.; Nemšák, S.; Schneider, C. M.; Crumlin, E. J.; et al. Direct Mapping of Band Positions in Doped and Undoped Hematite During Photoelectrochemical Water Splitting. J. Phys. Chem. Lett. 2017, 8, 5579-5586.

(24) Li, M.; Yang, Y.; Ling, Y.; Qiu, W.; Wang, F.; Liu, T.; Song, Y.; Liu, X.; Fang, P.; Tong, Y.; et al. Morphology and Doping Engineering of Sn-Doped Hematite Nanowire Photoanodes. Nano Lett. 2017, 17, 2490-2495.

(25) Sivula, K.; Zboril, R.; Le Formal, F.; Robert, R.; Weidenkaff, A.; Tucek, J.; Frydrych, J.; Gratzel, M. Photoelectrochemical Water Splitting with Mesoporous Hematite Prepared by a Solution-Based Colloidal Approach. J. Am. Chem. Soc. 2010, 132, 7436-44.

(26) Vichery, C.; Maurin, I.; Bonville, P.; Boilot, J.-P.; Gacoin, T. Influence of Protected Annealing on the Magnetic Properties of $\gamma$ $\mathrm{Fe}_{2} \mathrm{O}_{3}$ Nanoparticles. J. Phys. Chem. C 2012, 116, 16311-16318.

(27) Zandi, O.; Hamann, T. W. Enhanced Water Splitting Efficiency through Selective Surface State Removal. J. Phys. Chem. Lett. 2014, 5, $1522-1526$

(28) Si, W.; Haydous, F.; Babic, U.; Pergolesi, D.; Lippert, T. Suppressed Charge Recombination in Hematite Photoanode Via Protonation and Annealing. ACS Appl. Energy Mater. 2019, 2, 54385445.

(29) Kennedy, J. H.; Frese, K. W. Photooxidation of Water at $\alpha$ $\mathrm{Fe}_{2} \mathrm{O}_{3}$ Electrodes. J. Electrochem. Soc. 1978, 125, 709-714.

(30) Ling, Y.; Wang, G.; Reddy, J.; Wang, C.; Zhang, J. Z.; Li, Y. The Influence of Oxygen Content on the Thermal Activation of Hematite Nanowires. Angew. Chem., Int. Ed. 2012, 51, 4074-4079.

(31) Wang, J.; Perry, N. H.; Guo, L.; Vayssieres, L.; Tuller, H. L. On the Theoretical and Experimental Control of Defect Chemistry and Electrical and Photoelectrochemical Properties of Hematite Nanostructures. ACS Appl. Mater. Interfaces 2019, 11, 2031-2041.

(32) Yang, T.-Y.; Kang, H.-Y.; Sim, U.; Lee, Y.-J.; Lee, J.-H.; Koo, B.; Nam, K. T.; Joo, Y.-C. A New Hematite Photoanode Doping Strategy for Solar Water Splitting: Oxygen Vacancy Generation. Phys. Chem. Chem. Phys. 2013, 15, 2117-2124.

(33) Pu, A.; Deng, J.; Li, M.; Gao, J.; Zhang, H.; Hao, Y.; Zhong, J.; Sun, $\mathrm{X}$. Coupling Ti-Doping and Oxygen Vacancies in Hematite Nanostructures for Solar Water Oxidation with High Efficiency. J. Mater. Chem. A 2014, 2, 2491-2497.

(34) Kim, J. Y.; Youn, D. H.; Kim, J. H.; Kim, H. G.; Lee, J. S. Nanostructure-Preserved Hematite Thin Film for Efficient Solar Water Splitting. ACS Appl. Mater. Interfaces 2015, 7, 14123-14129.

(35) Carvalho, W. M., Jr.; Mendonça-Ferreira, L.; Costa, F. N.; Ferreira, F. F.; Muche, D. N. F.; Tofanello, R. A.; Castro, R. H. R.; Souza, F. L. Annealing Control of Hydrothermally Grown Hematite Nanorods: Implication of Structural Changes and $\mathrm{Cl}$ Concentration on Weak Ferromagnetism. J. Alloys Compd. 2019, 799, 83-88.

(36) Annamalai, A.; Shinde, P. S.; Subramanian, A.; Kim, J. Y.; Kim, J. H.; Choi, S. H.; Lee, J. S.; Jang, J. S. Bifunctional $\mathrm{TiO}_{2}$ Underlayer for $\alpha-\mathrm{Fe}_{2} \mathrm{O}_{3}$ Nanorod Based Photoelectrochemical Cells: Enhanced Interface and $\mathrm{Ti}^{4+}$ Doping. J. Mater. Chem. A 2015, 3, 5007-5013.

(37) Deng, J.; Zhong, J.; Pu, A.; Zhang, D.; Li, M.; Sun, X.; Lee, S.T. Ti-Doped Hematite Nanostructures for Solar Water Splitting with High Efficiency. J. Appl. Phys. 2012, 112, 084312.

(38) Xiao, J.; Huang, H.; Huang, Q.; Zhao, L.; Li, X.; Hou, X.; Chen, $\mathrm{H}$.; Li, Y. Suppressing the Electron-Hole Recombination Rate in Hematite Photoanode with a Rapid Cooling Treatment. J. Catal. 2017, 350, 48-55.

(39) Francisco, F.; Dias, P.; Ivanou, D.; Santos, F.; Azevedo, J.; Mendes, A. Synthesis of Host-Guest Hematite Photoelectrodes for Solar Water Splitting. ChemNanoMat 2019, 5, 911-920.

(40) Lopes, T.; Andrade, L.; Le Formal, F.; Gratzel, M.; Sivula, K.; Mendes, A. Hematite Photoelectrodes for Water Splitting: Evaluation of the Role of Film Thickness by Impedance Spectroscopy. Phys. Chem. Chem. Phys. 2014, 16, 16515-16523.

(41) Dotan, H.; Mathews, N.; Hisatomi, T.; Grätzel, M.; Rothschild, A. On the Solar to Hydrogen Conversion Efficiency of Photo- electrodes for Water Splitting. J. Phys. Chem. Lett. 2014, 5, 33303334.

(42) Schneider, C. A.; Rasband, W. S.; Eliceiri, K. W. NIH Image to ImageJ: 25 Years of Image Analysis. Nat. Methods 2012, 9, 671-675.

(43) Figueroa, S. J. A.; Mauricio, J. C.; Murari, J.; Beniz, D. B.; Piton, J. R.; Slepicka, H. H.; de Sousa, M. F.; Espíndola, A. M.; Levinsky, A. P. S. Upgrades to the XAFS2 Beamline Control System and to the Endstation at the LNLS. J. Phys.: Conf. Ser. 2016, 712, 012022.

(44) Ravel, B.; Newville, M. Athena, Artemis, Hephaestus: Data Analysis for X-Ray Absorption Spectroscopy Using IFEFFIT. J. Synchrotron Radiat. 2005, 12, 537-541.

(45) Barradas, N. P.; Jeynes, C.; Harry, M. A. RBS/Simulated Annealing Analysis of Iron-Cobalt Silicides. Nucl. Instrum. Methods Phys. Res., Sect. B 1998, 136-138, 1163-1167.

(46) Barradas, N. P.; Jeynes, C.; Webb, R. P. Simulated Annealing Analysis of Rutherford Backscattering Data. Appl. Phys. Lett. 1997, 71, 291-293.

(47) Le Formal, F.; Grätzel, M.; Sivula, K. Controlling Photoactivity in Ultrathin Hematite Films for Solar Water-Splitting. Adv. Funct. Mater. 2010, 20, 1099-1107.

(48) Bartesaghi, D.; Pérez, I. d. C.; Kniepert, J.; Roland, S.; Turbiez, M.; Neher, D.; Koster, L. J. A. Competition between Recombination and Extraction of Free Charges Determines the Fill Factor of Organic Solar Cells. Nat. Commun. 2015, 6, 7083.

(49) Dias, P.; Lopes, T.; Meda, L.; Andrade, L.; Mendes, A. Photoelectrochemical Water Splitting Using $\mathrm{WO}_{3}$ Photoanodes: The Substrate and Temperature Roles. Phys. Chem. Chem. Phys. 2016, 18, $5232-5243$.

(50) Apolinário, A.; Lopes, T.; Costa, C.; Araújo, J. P.; Mendes, A. M. Multilayered $\mathrm{WO}_{3}$ Nanoplatelets for Efficient Photoelectrochemical Water Splitting: The Role of the Annealing Ramp. ACS Appl. Energy Mater. 2019, 2, 1040-1050.

(51) Cornell, R. M.; Schwertmann, U. In The Iron Oxides: Structure, Properties, Reactions, Occurrences, and Uses; Wiley-VCH Verlag GmbH \& Co. KGaA: 2004; pp 9-38.

(52) Rettie, A. J. E.; Chemelewski, W. D.; Emin, D.; Mullins, C. B. Unravelling Small-Polaron Transport in Metal Oxide Photoelectrodes. J. Phys. Chem. Lett. 2016, 7, 471-479.

(53) Cornuz, M.; Grätzel, M.; Sivula, K. Preferential Orientation in Hematite Films for Solar Hydrogen Production Via Water Splitting. Chem. Vap. Deposition 2010, 16, 291-295.

(54) Nakau, T. Electrical Conductivity of $\alpha-\mathrm{Fe}_{2} \mathrm{O}_{3}$. J. Phys. Soc. Jpn. $1960,15,727-727$.

(55) Iordanova, N.; Dupuis, M.; Rosso, K. M. Charge Transport in Metal Oxides: A Theoretical Study of Hematite $\alpha-\mathrm{Fe}_{2} \mathrm{O}_{3}$. J. Chem. Phys. 2005, 122, 144305.

(56) Ungár, T. Microstructural Parameters from X-Ray Diffraction Peak Broadening. Scr. Mater. 2004, 51, 777-781.

(57) Williamson, G. K.; Hall, W. H. X-Ray Line Broadening from Filed Aluminium and Wolfram. Acta Metall. 1953, 1, 22-31.

(58) Oliveira, G. N. P.; Machado, P.; Pires, A. L.; Pereira, A. M.; Araújo, J. P.; Lopes, A. M. L. Magnetocaloric Effect and Refrigerant Capacity in Polycrystalline $\mathrm{YCrO}_{3}$. J. Phys. Chem. Solids 2016, 91, $182-188$.

(59) Proenca, M. P.; Sousa, C. T.; Pereira, A. M.; Tavares, P. B.; Ventura, J.; Vazquez, M.; Araujo, J. P. Size and Surface Effects on the Magnetic Properties of NiO Nanoparticles. Phys. Chem. Chem. Phys. 2011, 13, 9561-9567.

(60) Wilke, M.; Farges, F.; Petit, P.-E.; Brown, G. E., Jr.; Martin, F. Oxidation State and Coordination of Fe in Minerals: An Fe K-XANES Spectroscopic Study. Am. Mineral. 2001, 86, 714-730.

(61) Annamalai, A.; Subramanian, A.; Kang, U.; Park, H.; Choi, S. H.; Jang, J. S. Activation of Hematite Photoanodes for Solar Water Splitting: Effect of FTO Deformation. J. Phys. Chem. C 2015, 119, 3810-3817.

(62) Chu, W.-K.; Mayer, J. W.; Nicolet, M.-A. Chapter 1 Introduction. In Backscattering Spectrometry; Academic Press: 1978; pp 1-20. 
(63) Barradas, N. P. Rutherford Backscattering Analysis of Thin Films and Superlattices with Roughness. J. Phys. D: Appl. Phys. 2001, 34, 2109-2116.

(64) Barradas, N. P.; García Núñez, C.; Redondo-Cubero, A.; Shen, G.; Kung, P.; Pau, J. L. Analytical Simulation of RBS Spectra of Nanowire Samples. Nucl. Instrum. Methods Phys. Res., Sect. B 2016, $371,116-120$.

(65) Marusak, L. A.; Messier, R.; White, W. B. Optical Absorption Spectrum of Hematite, $\alpha \mathrm{Fe}_{2} \mathrm{O}_{3}$ near IR to UV. J. Phys. Chem. Solids 1980, 41, 981-984.

(66) Sivula, K.; Zboril, R.; Le Formal, F.; Robert, R.; Weidenkaff, A.; Tucek, J.; Frydrych, J.; Grätzel, M. Photoelectrochemical Water Splitting with Mesoporous Hematite Prepared by a Solution-Based Colloidal Approach. J. Am. Chem. Soc. 2010, 132, 7436-7444.

(67) Dimri, V. P.; Srivastava, R. P.; Vedanti, N. Chapter 5 Reservoir Geophysics: Some Basic Concepts. In Handbook of Geophysical Exploration: Seismic Exploration; Pergamon, 2012; Vol. 41, pp 89-118.

(68) Tauc, J. Optical Properties and Electronic Structure of Amorphous Ge and Si. Mater. Res. Bull. 1968, 3, 37-46. 